\title{
Anthropometric Indicators as a Tool for Diagnosis of Obesity and Other Health Risk Factors: A Literature Review
}

\author{
Paola Piqueras ${ }^{1 *}$, Alfredo Ballester ${ }^{1}$, Juan V. Durá-Gil ${ }^{1}$, Sergio Martinez-Hervas ${ }^{2,3,4,5 *}$, \\ Josep Redón ${ }^{6,7,8}$ and José T. Real ${ }^{2,3,4,5}$ \\ ${ }^{1}$ Instituto de Biomecánica de Valencia, Universitat Politècnica de Valencia, Valencia, Spain, ${ }^{2}$ Service of Endocrinology and \\ Nutrition, Hospital Clínico Universitario de Valencia, Valencia, Spain, ${ }^{3}$ Institute of Health Research of the Hospital Clinico \\ Universitario de Valencia (INCLINA), Valencia, Spain, ${ }^{4}$ Department of Medicine, University of Valencia, Valencia, Spain, \\ ${ }^{5}$ CIBER de Diabetes y Enfermedades Metabólicas Asociadas (CIBERDEM), Madrid, Spain, ${ }^{6}$ Department of Internal \\ Medicine, Hospital Clínico de Valencia, University of Valencia, Valencia, Spain, ${ }^{7}$ CIBER Fisiopatología Obesidad y Nutrición \\ (CB06/03), Instituto de Salud Carlos III, Madrid, Spain, ${ }^{8}$ Cardiovascular and Renal Risk Research Group, Institute of Health \\ Research of the Hospital Clinico Universitario de Valencia (INCLIVA), University of Valencia, Valencia, Spain
}

OPEN ACCESS

Edited by:

Pietro Cipresso,

University of Turin, Italy

Reviewed by:

Ferdinando Franzoni,

University of Pisa, Italy

Isabelle Mack,

Tübingen University

Hospital, Germany

*Correspondence:

Paola Piqueras

paola.piqueras@ibv.org

Sergio Martinez-Hervas

sergio.martinez@uv.es

Specialty section:

This article was submitted to Quantitative Psychology and

Measurement,

a section of the journal

Frontiers in Psychology

Received: 19 November 2020

Accepted: 07 June 2021

Published: 09 July 2021

Citation:

Piqueras P, Ballester A, Durá-Gil JV, Martinez-Hervas S, Redón J and

Real JT (2021) Anthropometric Indicators as a Tool for Diagnosis of Obesity and Other Health Risk

Factors: A Literature Review.

Front. Psychol. 12:631179.

doi: 10.3389/fpsyg.2021.631179
Obesity is characterized by the accumulation of an excessive amount of fat mass (FM) in the adipose tissue, subcutaneous, or inside certain organs. The risk does not lie so much in the amount of fat accumulated as in its distribution. Abdominal obesity (central or visceral) is an important risk factor for cardiovascular diseases, diabetes, and cancer, having an important role in the so-called metabolic syndrome. Therefore, it is necessary to prevent, detect, and appropriately treat obesity. The diagnosis is based on anthropometric indices that have been associated with adiposity and its distribution. Indices themselves, or a combination of some of them, conform to a big picture with different values to establish risk. Anthropometric indices can be used for risk identification, intervention, or impact evaluation on nutritional status or health; therefore, they will be called anthropometric health indicators (AHIs). We have found 17 AHls that can be obtained or estimated from 3D human shapes, being a noninvasive alternative compared to X-ray-based systems, and more accessible than high-cost equipment. A literature review has been conducted to analyze the following information for each indicator: definition; main calculation or obtaining methods used; health aspects associated with the indicator (among others, obesity, metabolic syndrome, or diabetes); criteria to classify the population by means of percentiles or cutoff points, and based on variables such as sex, age, ethnicity, or geographic area, and limitations.

Keywords: obesity, anthropometric health indicators, health, risk identification, fat distribution, 3D human shapes

\section{INTRODUCTION}

Overweight and obesity are the most prevalent metabolic disorders in developed countries. The prevalence of obesity has increased tremendously in recent decades (WHO | Noncommunicable diseases country profiles, 2018). In Spain, the estimated prevalence of overweight [body mass index (BMI), 25.0-29.9] in the adult population reaches $39.3 \%$, and the global prevalence of obesity (BMI > 30) is estimated at 21.6\% (Aranceta-Bartrina et al., 2016). 
Obesity is characterized by abnormal or excessive fat accumulation. Obesity has been associated with an increased risk of type 2 diabetes and cardiovascular disease, as well as other conditions such as cancer, mental health, and osteoarthritis, contributing to a decrease in both quality of life and life expectancy (Pischon et al., 2008; Di Angelantonio et al., 2016; Blüher, 2019).

The obese phenotype, however, is complex, and some patients have no obvious cardiometabolic effect. In this sense, obesity, but especially abdominal adiposity (central or visceral), induces or aggravates the presence of insulin resistance, which, in turn, leads to different metabolic disturbances, constituting a cluster of the obesity-driven alterations also known as the metabolic syndrome (Kahn et al., 2019).

Taking into account that obesity is a known independent risk factor for non-communicable diseases and that the increasing prevalence of obesity worldwide confers a significant global public health burden (Bray et al., 2016), it is necessary to prevent, detect, and appropriately treat obesity to reduce the future health and economic costs of this problem. The first step to achieve this is to reliably diagnose individuals. In this sense, many anthropometric indices associated with adiposity and its distribution have emerged, such as the widely known BMI, waist-to-hip ratio (WHR), or body fat percentage (BFP).

Anthropometric indices have been used for different purposes becoming indicators for risk identification, intervention, or impact assessment on nutritional status or health. Therefore, from now on, these indices will be called anthropometric health indicators (AHIs). There are many studies related to AHIs in the literature in which estimation methods are proposed, cutoffs are provided for different populations, or in which their reliability and validity are analyzed. However, its impact as a whole has not been fully established and analyzed. The aim of this review is to provide an overview of different AHIs and to review in depth those that can be obtained or estimated from 3D human shapes and their usefulness for assessing obesity and other health risk factors. These AHIs are on the rise, especially with the potential of emerging $3 \mathrm{D}$ imaging devices, compared to traditional laboratory methods, which are invasive, require well-trained laboratory personnel, and are often too expensive for field settings.

\section{METHODS}

\section{Search Criteria}

A total of 42 AHIs have been previously identified. In order to categorize them, two questions were raised:

- Can the AHI be obtained or estimated from 3D human shapes?

- Does the AHI have enough available classification criteria? Can the AHI be used to assess health risk of individuals even if limited?

Based on the answers to these two questions, the AHIs have been grouped into four categories (Figure 1). A list of the AHIs grouped into the four categories is shown in Table $\mathbf{1 .}$

Methods of the analysis and inclusion criteria were specified in advance and documented in a protocol.

\section{Inclusion Criteria}

The specific inclusion and exclusion criteria are shown in Table 2. Basically, criteria for the inclusion of studies included the following:

1. Studies published from January 1956 until September 30, 2020.

2. Studies performed in humans.

3. Studies published in English language.

4. Studies shown a direct anthropometric measurement, prediction equations, models, or methods based on equipment measurements such as bioelectrical impedance analysis (BIA) or dual-energy X-ray absorptiometry (DXA).

\begin{tabular}{|l|}
\hline \multicolumn{1}{|c|}{ Category 1} \\
Can the AHI be obtained or estimated \\
from $3 D$ human shapes? YES \\
Does the AHI have enough available \\
classification criteria? YES
\end{tabular}

\begin{tabular}{|l|}
\hline \multicolumn{1}{|c|}{ Category 3} \\
Can the AHI be obtained or estimated \\
from $3 D$ human shapes? NO \\
Does the AHI have enough available \\
classification criteria? YES
\end{tabular}

\begin{tabular}{l} 
Category 2 \\
$\begin{array}{l}\text { Can the AHI be obtained or estimated } \\
\text { from 3D human shapes? YES } \\
\text { Does the AHI have enough available } \\
\text { classification criteria? NO }\end{array}$ \\
\hline \multicolumn{1}{|c|}{ Category 4} \\
Can the AHI be obtained or estimated \\
from 3D human shapes? NO \\
$\begin{array}{l}\text { Does the AHI have enough available } \\
\text { classification criteria? NO }\end{array}$ \\
\hline
\end{tabular}

FIGURE 1 | Classification of AHIs into four categories. 
TABLE 1 | List of AHls grouped into the four categories.

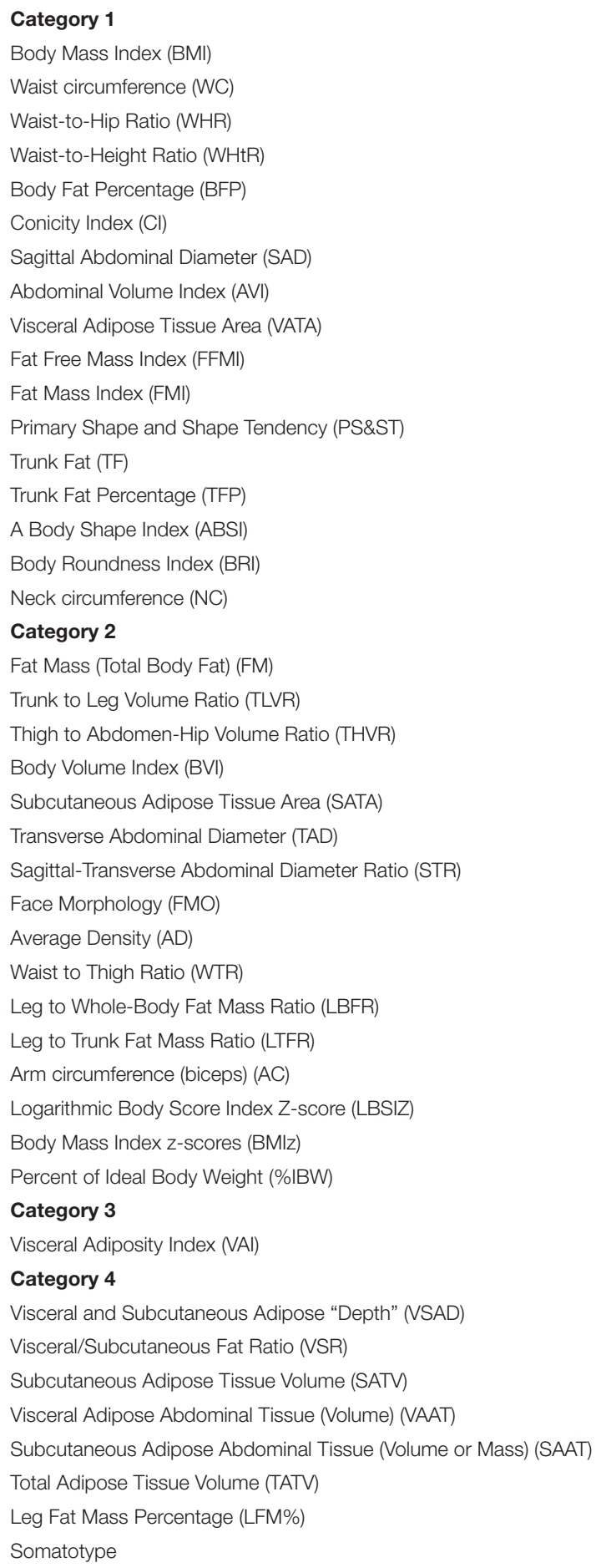

5. Studies provided the health aspects associated with the indicator, among others, obesity, metabolic syndrome, or diabetes.

6. Studies presented information on criteria to classify the population-by means of percentiles or cutoff points, and
TABLE 2 | Inclusion and exclusion criteria according to PICO.

\begin{tabular}{|c|c|c|}
\hline Criteria & Inclusion & Exclusion \\
\hline Population & Human. Adults and/or children & Animal \\
\hline Intervention & $\begin{array}{l}\text { AHI obtained or estimated from 3D } \\
\text { human shapes; AHI with availability of } \\
\text { classification criteria }\end{array}$ & \\
\hline Outcome & $\begin{array}{l}\text { AHI's obtaining method; AHI's associated } \\
\text { health aspect; AHI's classification criteria; AHI's } \\
\text { limitation }\end{array}$ & \\
\hline Comparison & Other method to assess body composition & \\
\hline Date & Cutoff date limit of 1956-2020 was applied & \\
\hline Language & Only studies written in English were included & \\
\hline Field of search & Title or abstract & \\
\hline
\end{tabular}

based on variables such as sex, age, ethnicity, or geographic area-and limitations.

\section{Literature Research}

The literature search was performed in the electronic database of PubMed, including the 17 AHIs, which can be obtained or estimated from 3D human shapes (Table 1; Category 1).

The key words analyzed and the search strategy are shown in detail as follows: (diabetes OR metabolic syndrome OR cardiometabolic OR Cut-off OR cutoff OR cut off OR Blood pressure OR Classification OR obesity OR cardiovascular disease OR fat mass OR visceral fat OR fat distribution OR mortality OR children OR adolescent OR gender OR formula OR bioelectrical impedance accuracy OR anthropometric health indicator OR body composition assessment OR risk OR criteria OR classification OR health OR BIA OR bioelectrical impedance analysis OR dual-energy X-ray absorptiometry OR DXA OR ethnicity OR TC OR human shape OR MRI OR 3D) AND (Body mass index OR waist circumference OR waist-to-hip ratio OR waist-to-height ratio OR body fat percentage OR conicity index OR sagittal abdominal diameter OR Abdominal Volume Index OR Visceral Adipose Tissue Area OR Fat Free Mass Index OR Fat Mass Index OR Primary Shape and Shape Tendency OR Trunk Fat OR Trunk Fat Percentage Body Shape Index OR Body Roundness Index OR Neck circumference).

We also applied the restrictions included in the inclusion and exclusion criteria (Table 2).

\section{Eligibility and Data Abstraction}

We reviewed the references identified by the search method specified above. The titles and abstracts were screened for inclusion. Full-text records were collated for the articles decided to be included and were further screened. Additional references were identified by manually searching the bibliographies of these articles.

Eligibility assessment and data abstraction were performed independently in an unblinded standardized manner by two reviewers ( $\mathrm{PP}$ and $\mathrm{SM}-\mathrm{H})$. Abstracted data included eligibility criteria and methodological quality. Disagreements between reviewers were resolved by consensus. 

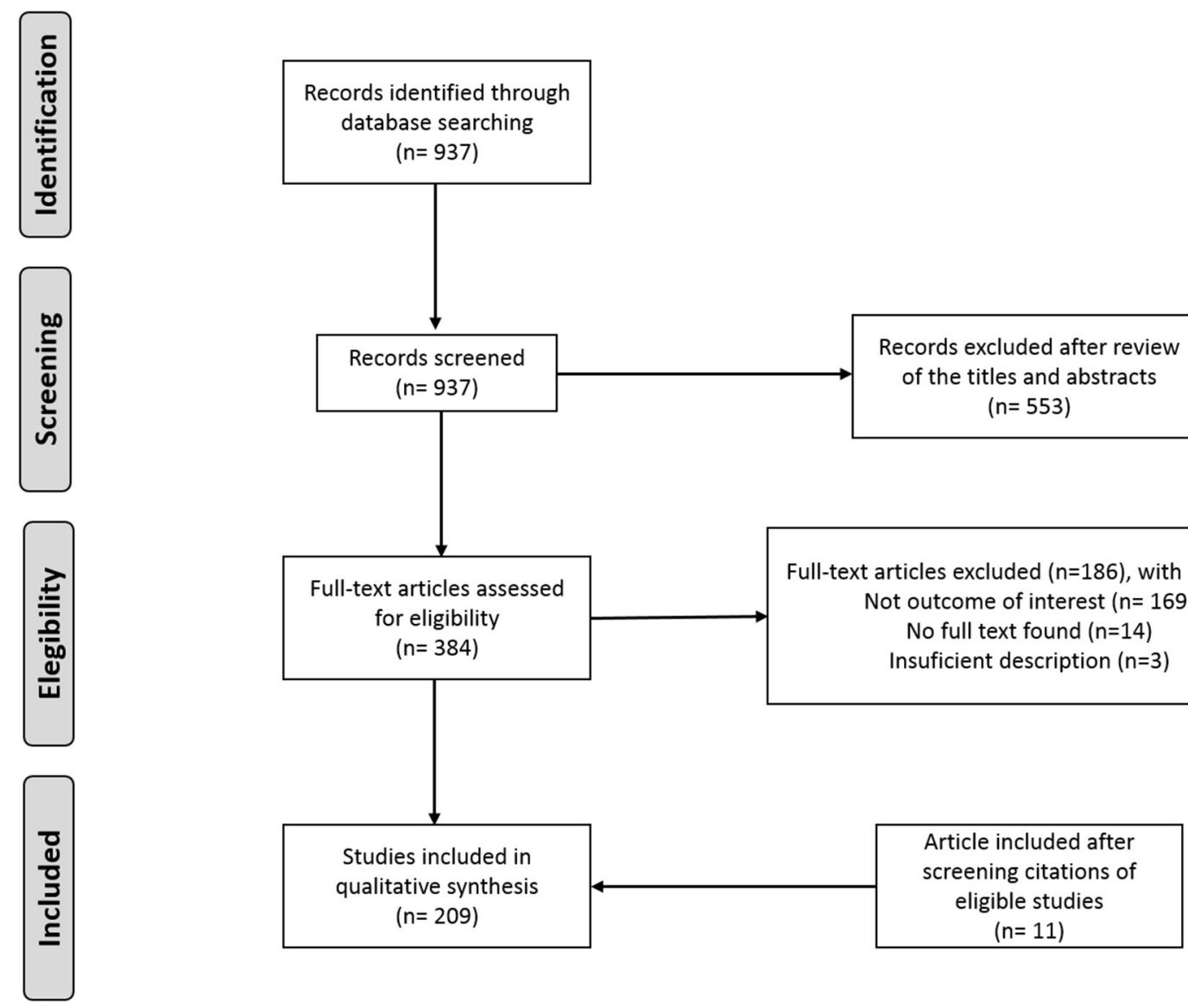

FIGURE 2 | Flow diagram of the results from the literature search and the study selection.

\section{RESULTS}

A total of 42 AHIs have been identified and categorized into four groups according to the possibility of estimation from 3D human shapes and the availability of classification criteria (Figure $\mathbf{1}$ and Table 1). This study deeply reviews the 17 AHIs included in category 1 (Table 1).

\section{Literature Selection}

The literature search in PubMed identified 937 records. All of them were screened. Finally, 209 of these records were considered eligible for inclusion in the current literature review. A detailed flow diagram of the results from the literature search and the study selection is shown in Figure 2.

\section{AHls Selected for the Review}

A list of the 17 AHIs reviewed is given in Table 1. The main body measurements used in the literature for their estimation are gathered in Table 3.

For each AHI, the main estimation or obtaining methods, health aspects associated, classification criteria, and limitations are described. The purpose of this paper is not to perform a comprehensive review of all published information, but to provide the most relevant data on each AHI.

\section{Body Mass Index}

It is a simple and widespread indicator for the diagnosis of obesity. It is widely used as an index of relative weight.

\section{Method}

It is calculated as the ratio between body mass (in kilograms) and height squared (in meters).

$$
B M I=\frac{\operatorname{Body} \text { mass }(\mathrm{kg})}{\operatorname{Height}^{2}\left(\mathrm{~m}^{2}\right)}
$$

\section{Associated Health Aspects}

Both high and low BMIs are associated with an increased risk of developing chronic diseases and mortality. Different studies have shown a U-shaped association between BMI (higher than $25 \mathrm{~kg} / \mathrm{m}^{2}$ and lower than $18.5-20 \mathrm{~kg} / \mathrm{m}^{2}$ ) and all-cause mortality (Pischon et al., 2008; Song et al., 2015; Yi et al., 2015; Aune et al., 2016; Di Angelantonio et al., 2016). Furthermore, excess body weight has been associated with cancer burden (Lauby-Secretan et al., 2016; Sung et al., 2019; Hu et al., 2020). In the same line, 
TABLE 3 | Main parameters obtained from 3D human shapes and used to estimate AHIs.

\begin{tabular}{ll}
\hline Body measurements & AHIs associated \\
\hline Weight & BMI, BFP, CI, VATA, FFMI, FMI, and ABSI \\
Height & BMI, WHtR, BFP, CI, VATA, FFMI, FMI, ABSI, and \\
& BRI \\
Waist circumference & WC, WHR, WHtR, BFP, Cl, AVI, VATA, FFMI, FMI, \\
& TF, TFP, ABSI, and BRI \\
Hip circumference & WHR, BFP, and AVI \\
Thigh circumference & VATA and BFP \\
Volumes & BFP, FMI, PS\&ST, and TF \\
Surface areas & BFP and PS\&ST \\
Other body measurements & BFP, FFMI, FMI, PS\&ST, and TF \\
Sagittal abdominal diameter & SAD \\
Neck circumference & NC \\
\hline
\end{tabular}

evidence from several studies indicates that obesity or high BMI was associated with an increased risk of CVD events (Dwivedi et al., 2020) and an increased risk of diabetes (Ford et al., 1997; Resnick et al., 2000).

\section{Classification Criteria}

There are different cutoffs of BMI to classify individuals. BMI is considered normal when ranging from 18.5 to $24.9 \mathrm{~kg} / \mathrm{m}^{2}$. Overweight is considered when BMI ranges from 25 to 29.9 $\mathrm{kg} / \mathrm{m}^{2}$, and obesity when BMI is over $30 \mathrm{~kg} / \mathrm{m}^{2}$. On the contrary, thinness is considered when BMI is under $18.5 \mathrm{~kg} / \mathrm{m}^{2}$ (Yanovski and Yanovski, 2002; Bray et al., 2016). For children and adolescents, there have been developed reference-specific age and sex cutoffs to define child overweight and obesity (Rolland-Cachera et al., 1982; Deurenberg et al., 1991; Cole et al., $2000,2007)$. In addition, in older subjects, the actual cutoffs to classify individuals should be modified. Furthermore, there are differences in body composition between populations of different ethnic origin. Because of that, different BMI cutoffs have been suggested for Asian population (WHO Expert Consultation, 2004; Wildman et al., 2004).

\section{Limitations}

BMI is the most widely used anthropometric index to estimate the overall body fatness. However, this index is a measure of excess weight rather than excess body fatness. The BMI has the advantage of simplicity (Romero-Corral et al., 2008), but it has deficiencies because it cannot directly address the aspects of body composition such as visceral fat or fat distribution (Ashwell et al., 2012; Böhm and Heitmann, 2013; Britton et al., 2013). Moreover, the BMI as an index for fat mass (FM) is therefore less reliable in the elderly because at an older age, there is a redistribution of body fat to the abdominal region (Seidell and Visscher, 2000). Furthermore, the morbidity associated with excess body weight varies among individuals of similar BMI and from different ethnicity (WHO Expert Consultation, 2004; Wildman et al., 2004). BMI is also inappropriate to classify subjects in the case of body builders or athletes because these subjects could be classified as obese. Finally, because BMI depends on age and height, adult population criteria should not be used to classify pre-pubertal and pubertal population (Rolland-Cachera et al., 1982). Gender should be also considered in these subjects.

\section{Waist Circumference}

It is an easy and practical anthropometric index to evaluate the visceral fat in adults (Lemieux et al., 1996), which is wellcorrelated with the BFP (Heo et al., 2013).

\section{Method}

It is defined as the circumference at the waist; however, there is diversity in its measurement protocol, and there is currently no consensus (Ross et al., 2008). Some of the main leading health authorities consider the waist level to be located at the approximate midpoint between the lower margin of the last palpable rib and the top of the iliac crest (WHO, IDF, ISAK, ISO 7250, ASTM); or at the top of the iliac crest (NHANES III, NCEP ATP III); or at the narrowest waist (ASM); or at the level of the navel (MESA study).

\section{Associated Health Aspects}

Waist circumference is one of the main components of the metabolic syndrome (Expert Panel on Detection, Evaluation and Treatment of High Blood Cholesterol in Adults, 2001; Alberti et al., 2006). Increasing values of WC are an important cardiovascular risk factor, as well as are associated with other cardiovascular risk factors (Pouliot et al., 1994; Han et al., 1995; Rexrode et al., 1998; Dobbelsteyn et al., 2001). Raising of WC has also been related to type 2 diabetes risk (Chan et al., 1994; Carey et al., 1997; Wei et al., 1997). Finally, WC is strongly associated with all-cause and cardiovascular mortality (Pischon et al., 2008; Zhang et al., 2008; Cerhan et al., 2014; Song et al., 2015).

\section{Classification Criteria}

Diverse cutoffs have been proposed as criteria of metabolic syndrome. Recommended cutoffs (equal or higher) for WC vary for different ethnic groups and by gender (Balkau and Charles, 1999; Organization, 1999; Expert Panel on Detection, Evaluation and Treatment of High Blood Cholesterol in Adults, 2001; Alberti et al., 2006). The cutoffs for Europids are $94 \mathrm{~cm}$ for male and $80 \mathrm{~cm}$ for female. However, the cutoffs for central obesity adopted in the United States are $102 \mathrm{~cm}$ for male and $88 \mathrm{~cm}$ for female. Cutoffs recommended for South Asians, Chinese, and Japanese are 90 and $80 \mathrm{~cm}$ for men and women, respectively, which have been validated in a series of studies (Li et al., 2002; Lin et al., 2002; Zhou and Cooperative Meta-Analysis Group of the Working Group on Obesity in China, 2002; Tan et al., 2004; Wildman et al., 2004). For ethnic South and Central Americans, the cutoffs recommended are the South Asian recommendations until more specific data are available. Finally, for sub-Saharan Africans and for Eastern Mediterranean and Middle East individuals, the cutoffs recommended are the European recommendations until more specific data will be available (Alberti et al., 2006).

These criteria have also been modified for use in children and adolescents (Cook et al., 2003; Zimmet et al., 2007). The criteria established by the IDF specify cutoff points for the WC divided into the following age groups: 6-10, 10-16, and 16 years or more. It is suggested that below 16 years of age specific diagnostic criteria (higher than 90th percentile of the population) and above 
16 years the IDF criteria for adults would be used (Zimmet et al., 2007).

\section{Limitations}

The procedure of waist measurement is not univocally standardized. Moreover, in subjects with BMI higher than $35 \mathrm{~kg} / \mathrm{m}^{2}$, it is difficult to measure the WC. Also, WC is influenced by gender, age, and ethnicity. Finally, WC does not differentiate between visceral fat and subcutaneous fat.

\section{Waist-to-Hip Ratio}

It is considered an indicator of visceral fat.

\section{Method}

It is defined as the quotient between the WC and the hip circumference (HC), in the same unit (dimensionless).

$$
W H R=\frac{W C}{H C}
$$

The WC can be measured by means of any of the abovementioned protocols. $\mathrm{HC}$ is commonly measured at the level of the greatest projection at the back of the body (buttocks) (WHO, IDF, ISAK, ISO 7250, ASTM, NHANES III).

\section{Associated Health Aspects}

Waist-to-hip ratio has been associated with an increased risk of death, cardiovascular disease, and type 2 diabetes (Dalton et al., 2003; Motamed et al., 2015; Ross et al., 2020).

\section{Classification Criteria}

The World Health Organization recommended a WHR cutoff of 0.8 for women and 1 for men, as point used to show central obesity WHO Consultation on Obesity (1997).

\section{Limitations}

In many cases, ratios induce a loss of information and are not the most suitable to evaluate the visceral fat (van der Kooy et al., 1993). Furthermore, when BMI is higher than $35 \mathrm{~kg} / \mathrm{m}^{2}$, there is more inaccuracy. WHR is also influenced by gender. Finally, there is not specific data for children.

\section{Waist-to-Height Ratio}

It is a measure of body fat distribution. It is also called Index of Central Obesity (ICO).

\section{Method}

It is defined as the quotient between the WC and the height, in the same unit (dimensionless).

$$
W H t R=\frac{W C}{\text { Height }}
$$

\section{Associated Health Aspects}

WHtR is a good predictor of metabolic risk, even better than BMI and WC (Browning et al., 2010; Ashwell et al., 2012). WHtR has been associated with several chronic diseases (Ashwell et al., 2012, 2014). Higher values of WHtR have been associated with higher cardiometabolic risk (diabetes, hypertension, dyslipidemia, metabolic syndrome, and cardiovascular disease) (Ashwell et al., 2012; Han et al., 2017; Wang et al., 2018). Furthermore, WHtR has also been associated with cardiovascular and all-cause mortality (Schneider et al., 2010; Song et al., 2015).

\section{Classification Criteria}

The proposed cutoff value for WHtR as a marker of metabolic risk is 0.5 for different adult populations (Ashwell et al., 2012; Cai et al., 2013).

\section{Limitations}

There are no specific data for children.

\section{Body Fat Percentage}

It is defined as the amount of FM as a percentage of the total body mass. The BFP is a core component of body composition, and it is strongly associated with obesity and the metabolic syndrome.

\section{Method}

There is a wide diversity of methods and models used to estimate it. However, there is not a universally recommended method to estimate BFP nor other important components of body composition (Wells and Fewtrell, 2006; Duren et al., 2008).

Body fat percentage can be estimated from body density, usually with Siri's and BroŽek's equations for adults (Siri, 1956; BroŽek et al., 1963). For children, there are equations similar to Siri's with age- and sex-specific constants (Lohman, 1989; Weststrate and Deurenberg, 1989; Wells et al., 2010).

Body density can be estimated with models based on skinfolds, such as age- and sex-specific equations for adults (Durnin and Womersley, 1974; Jackson and Pollock, 1978; Jackson et al., 1980), regression equations for adults involving as well WC (Lean et al., 1996), and regression equations for boys and girls of different maturation level (Deurenberg et al., 1990).

Body density can also be obtained by means of the following equation:

$$
\operatorname{Body} \text { density }(\mathrm{kg} / \mathrm{l})=\frac{\operatorname{Body} \text { mass }(\mathrm{kg})}{\text { Body volume }(l)}
$$

where body volume can be obtained through magnetic resonance imaging (MRI); computed tomography (CT); underwater weighing (UWW); air displacement plethysmography (ADP); or through $3 \mathrm{D}$ scanners. Ng et al. (2016) correlated this latter body volume measurement with ADP volume and volume derived from DXA output using the equations of Wilson et al. (2012). Bourgeois et al. (2017) found good correlations for adults between the total body volume measured by diverse optical devices and that obtained from ADP and derived from DXA.

Body fat percentage can also be estimated by means of anthropometric measurements. Slaughter et al. (1988) establish regression equations for the prediction of BFP from the sum of two skinfolds in children and youth. Paul Deurenberg et al. (1991) propose a formula relating BFP to BMI, age, and sex for adults over 15 years and children under 15 years. Lean et al. (1996) propose 12 regression equations for adults predicting BFP for each sex group considering different combinations of variables: WC, age, triceps skinfold thickness, BMI, and other 
anthropometric measurements. Gallagher et al. (2000) developed prediction equations of BFP based on BMI, age, sex, and ethnicity, based on data collected from adults of three ethnic groups (White, African American, and Asian). Taylor et al. (2002) predict BFP in children and adolescents aged 3-18 years at BMI cutoffs at each age equivalent to overweight and obesity in adults. Wang et al. (2003) correlate BFP in adults of both sexes with WC measured at four commonly used sites. Bergman et al. (2011) propose a formula relating BFP to $\mathrm{HC}$ and height for adult men and women of different ethnicities, named by its authors body adiposity index (BAI). Gómez-Ambrosi et al. (2012) relate BFP to BMI, age, and sex by means of a formula for adults named Clínica Universidad de Navarra-Body Adiposity Estimator (CUN-BAE) by its authors. Lee et al. (2017) propose prediction equations of BFP for adults based on age, race, height, weight, circumference, and skinfold measures. Woolcott and Bergman (2018) propose an estimator of BFP for adults, named relative fat mass (RFM) based on height, WC, and sex. The reference method used in these studies for BFP estimation was DXA. Recently, Harty et al. (2020) used a rearrangement of the four-component model of Wang et al. (2002) as a reference to propose a new formula for predicting BFP from a set body metrics derived from an optical scanner (body surface area, and upper arm, calf, thigh, and upper and lower abdomen circumferences) and machine learning. This new formula is presented in two branches, one for leaner subjects and another one for larger subjects, to provide a better prediction for the leaner group.

Body fat percentage has also been derived from the wholebody silhouettes obtained from DXA scans in children aged 6-16 years (Xie et al., 2015).

Body fat percentage has also been correlated with 3D body shapes (shape descriptors), using perceptual-level geometry features to increase the prediction accuracy of regression models based on descriptors derived from direct 3D geometry, such as circumferences, surface areas, or volumes (Lu et al., 2018).

Also, Carletti et al. (2018) have investigated the possibility of performing image-based BFP estimation associated with DXA with depth images of fit male subjects, obtaining reasonably good accuracy.

\section{Associated Health Aspects}

High BFP has been associated with a high prevalence of cardiometabolic dysregulation, metabolic syndrome, type 2 diabetes, and cardiovascular risk factors (Romero-Corral et al., 2008; Gómez-Ambrosi et al., 2011; Shea et al., 2012; Kim et al., 2013; Ramírez-Vélez et al., 2017; Jia et al., 2018; Park et al., 2018; Escobedo-de la Peña et al., 2020). BFP has also been associated with a reduced survival (Padwal et al., 2016) and an increased risk of cardiovascular disease (Dervaux et al., 2008; Si et al., 2020) and cancer (Si et al., 2020).

\section{Classification Criteria}

Body fat percentage differs across populations (Deurenberg and Deurenberg-Yap, 2003). The BFP cutoffs for obesity in adult Caucasians proposed by the WHO are $25 \%$ for men and $35 \%$ for women, corresponding to a BMI of $30 \mathrm{~kg} / \mathrm{m}^{2}$ (WHO | WHO | Physical status: the use and interpretation of anthropometry,
2020). There are also reports of BFP ranges for different ethnic groups: White, African American, and Asian (Gallagher et al., 2000). In the Chinese adult population, BFP cutoffs for obesity and for predicting the risk of cardiometabolic abnormalities have been proposed as $24 \%$ for men and $33 \%$ for women (Jia et al., 2018). There are also reference percentiles for children and adolescents according to age, gender (Taylor et al., 2002), and race (Mueller et al., 2004).

\section{Limitations}

Body fat percentage is age-, gender-, and ethnic-dependent (Deurenberg and Deurenberg-Yap, 2003). The current definitions of obesity using BFP are based on Western populations and probably need to be modified for Asian population.

\section{Conicity Index}

It is a simple anthropometric index of body fat distribution to assess the central obesity with high accuracy (Valdez et al., 1993; Roriz et al., 2014).

\section{Method}

Conicity index has been defined as Valdez (1991):

$$
\text { Conicity Index }(C I)=\frac{W C(m)}{0,109 \sqrt{\frac{\text { Weight }(\mathrm{kg})}{\text { Height }(\mathrm{m})}}}
$$

\section{Associated Health Aspects}

Conicity index has been associated with an excellent predictive capacity of metabolic syndrome in adolescents (Cristine Silva et al., 2020) and in older people (Ceolin et al., 2019). Furthermore, CI has demonstrated to be a good predictor of future diabetes (Andrade et al., 2016; Wang et al., 2019; Hernández-Vásquez et al., 2020) and hypertension (Andrade et al., 2016; Hernández-Vásquez et al., 2020). Thus, CI can be considered a good indicator of high cardiovascular risk (Tonding et al., 2014; Motamed et al., 2015), although it was not associated with coronary heart disease incidence in the population from the Framingham Heart Study (Kim et al., 2000).

\section{Classification Criteria}

Some cutoffs have been described in different populations (Almeida et al., 2009; Gadelha et al., 2016; Motamed et al., 2017; Filgueiras et al., 2019).

\section{Limitations}

There is a lack of specific cutoffs for clinical practice.

\section{Sagittal Abdominal Diameter}

It is also referred to as abdominal height, which is well-correlated with abdominal visceral adipose tissue accumulation (Kvist et al., 1988; Kahn and Williamson, 1993; van der Kooy et al., 1993; Pouliot et al., 1994; Zamboni et al., 1998; Clasey et al., 1999), which is even better than WC and BMI (Yim et al., 2010).

\section{Method}

It measures the anteroposterior diameter of the abdomen, usually in the supine position. It can be measured with an abdominal 
caliper (de Souza and de Oliveira, 2013; Firouzi et al., 2018) or by diagnostic imaging techniques.

\section{Associated Health Aspects}

Sagittal abdominal diameter has been associated with components of the metabolic syndrome (Mukuddem-Petersen et al., 2006; Guzzaloni et al., 2009) and insulin resistance (Risérus et al., 2004; Petersson et al., 2007), which is a good predictor of glucose dysregulation and diabetes incidence (Gletsu-Miller et al., 2013; Pajunen et al., 2013; Kahn et al., 2014; Firouzi et al., 2018). Furthermore, SAD is strongly associated with cardiovascular risk (Richelsen and Pedersen, 1995; Kahn et al., 1996a; Gustat et al., 2000; Ohrvall et al., 2000; Rådholm et al., 2017) and increased mortality (Seidell et al., 1994; Kahn et al., 1996b; Empana et al., 2004; Iribarren et al., 2006). Finally, SAD has also been associated with the incidence of dementia (Whitmer et al., 2008).

\section{Classification Criteria}

There have been described cutoffs of SAD associated with elevated cardiometabolic risk in adults (Risérus et al., 2010). Furthermore, there are also cutoffs of SAD associated with the presence of obesity in children (Al-Daghri et al., 2010).

\section{Limitations}

Currently, one major obstacle for SAD utilization is the lack of widely acceptable reference ranges or cutoff values to assign to the risk categories of SAD (Vasques et al., 2015). Furthermore, the utilization of $S A D$ requires a specific validation for each ethnicity.

\section{Abdominal Volume Index}

It is an index that estimates the overall abdominal volume.

\section{Method}

This index is proposed by Guerrero-Romero and RodríguezMorán (2003) consisting of a formula that estimates the overall abdominal volume for adults through $\mathrm{WC}$ and $\mathrm{HC}$ :

$$
A V I=\frac{2(W C)^{2}+0.7(W C-H C)^{2}}{1,000}
$$

where WC is the minimum circumference at the umbilicus level, and $\mathrm{HC}$ is the maximum circumference at the symphysis of pubis level.

\section{Associated Health Aspects}

Abdominal volume index is a reliable and easy tool for the estimation of obesity (Guerrero-Romero and Rodríguez-Morán, 2003). Even it was suggested that it is a better index to assess the accumulation of fat in the abdominal area and is able to more accurately assess the BFP (Ehrampoush et al., 2017). AVI has been associated with metabolic syndrome in adolescents (Perona et al., 2019) and in adults (Motamed et al., 2017; Wang et al., 2017), with glucose dysregulation and diabetes (Guerrero-Romero and Rodríguez-Morán, 2003; Mamtani and Kulkarni, 2005) and with diabetes prediction (Wang et al., 2019). Also, AVI has been associated with cardiovascular risk (Motamed et al., 2015; Wang et al., 2018).

\section{Classification Criteria}

Although there are few data, cutoffs of AVI for the estimation of obesity have been described, suggesting that an AVI of $\geq 24.5$ liters was associated with obesity (Guerrero-Romero and Rodríguez-Morán, 2003).

\section{Limitations}

There is a lack of specific cutoffs for clinical practice.

\section{Visceral Adipose Tissue Area}

It is the surrounding area of adipose tissue in the visceral area, most commonly located at the level of the umbilicus (L4/5).

\section{Method}

Currently, CT and MRI are the gold standard methods for the quantitative evaluation of intra-abdominal adipose tissue (Shuster et al., 2012).

Brambilla et al. (2006) estimate VATA for adults with the WC by means of a regression formula. The model proposed by Samouda et al. (2013) correlates VATA with the WC and proximal thigh circumferences, BMI, and age, for adult men and women. Kuk et al. (2005) also obtained regression equations for adult men and women relating WC to VAT depending on sex and age.

\section{Associated Health Aspects}

Measurement of VATA is an accurate determination of adipose depot (Thaete et al., 1995). VATA has been associated with metabolic risk factors (Rosito et al., 2008). VATA has been associated with coronary stenosis and the presence and characteristics of coronary plaques (Ohashi et al., 2010; Kang et al., 2014).

\section{Classification Criteria}

There are not specific cutoffs for the general population. However, some cutoffs have been proposed. Various studies have defined VATA cutoffs associated with different components of the metabolic syndrome in Caucasians (Nicklas et al., 2003; Katzmarzyk et al., 2013), African American (Katzmarzyk et al., 2013), and Asian (Kim et al., 2006). In the same line, Seo et al. (2009) proposed the cutoffs for the presence of the metabolic syndrome.

\section{Limitations}

There is a lack of specific cutoffs for clinical practice.

\section{Fat-Free Mass Index}

This index is associated with muscle mass.

\section{Method}

Fat-free mass index has been estimated by means of demographic information and components derived from the whole-body silhouettes obtained from DXA scans in children aged 6-16 years (Xie et al., 2015).

A good correlation of biomechanical variables with the FFMI was obtained by Campbell and Vallis (2014) in a stepwise regression. The resulting prediction equation that represents the largest FFMI variability in the study included forearm 
circumference (FC), BMI, maximum grip strength (MG), and the standard deviation of the double support time (SDDST) as predictor variables.

The FFMI is also obtained as the quotient between fat-free body mass (FFM) (in kilograms) and height squared (in meters).

$$
\operatorname{FFMI}\left(\frac{\mathrm{kg}}{\mathrm{m}^{2}}\right)=\frac{\text { FFM }(\mathrm{kg})}{\text { Height }^{2}\left(\mathrm{~m}^{2}\right)}
$$

Lee et al. (2017) proposed the anthropometric prediction equations of FFM for adults based on age, race, height, weight, circumference, and skinfold measurements.

By definition, FFM can also be estimated from the BFP:

$$
F F M(k g)=\text { Body mass }\left(1-\frac{B F P}{100}\right)
$$

Fat-free mass can also be estimated by subtracting the FM from the total body mass.

$$
F F M=\text { Body mass }-F M
$$

This way, some prediction equations described in the next section have also been used to estimate FFM (Wang et al., 2003; Ng et al., 2016).

\section{Associated Health Aspects}

Fat-free mass index has been described in children, adults, and elderly subjects, as an indicator of nutritional status (VanItallie et al., 1990; Barlett et al., 1991; Schutz et al., 2002). Moreover, low FFMI has been associated with a higher risk of mortality in the general population (Zhu et al., 2003; Sørensen et al., 2020) and in older men (Graf et al., 2015). Also, FFMI had a strong positive relationship with blood pressure in children (Zhang and Wang, 2011).

\section{Classification Criteria}

There have been described percentiles of FFMI in Caucasians for age and gender (Schutz et al., 2002) and predicted FFMI by gender and ethnicity (Caucasian, African American, Hispanic, and Asian), according to age groups (Hull et al., 2011; Lu et al., 2012; Jin et al., 2019). Furthermore, percentiles of FFMI for the U.S. population aged 25-80 years, stratified by sex and independent of race-ethnicity, have been described (Kudsk et al., 2017). Also, age-based reference values for FFMI have been described for healthy children and adolescents from the United States (Shypailo and Wong, 2020) and adolescents from Spain (Durá-Travé et al., 2020).

\section{Limitations}

Fat-free mass index is age-, gender-, and ethnic-dependent. Furthermore, more data are necessary for children.

\section{Fat Mass Index}

This index is associated with FM.

\section{Method}

The FMI is calculated as the quotient between FM (in kilograms) and height squared (in meters).

$$
F M I\left(\frac{k g}{m^{2}}\right)=\frac{F M(k g)}{\text { Height }^{2}\left(m^{2}\right)}
$$

Wang et al. (2003) correlate WC measured at four commonly used sites with body FM in adults of both sexes. $\mathrm{Ng}$ et al. (2016) propose a model to estimate FM from the WC, the waist width, the average leg volume, sex, and the torso volume obtained from 3D scan measurements. FM has also been correlated with the central obesity depth, thigh volume, sex, and torso volume measured by stereovision body imaging (Lee et al., 2015). Farina et al. (2016) establish sex-specific regression models to predict FM from height, weight, and parameters obtained from a single $2 \mathrm{D}$ side view photo taken with a smartphone, with promising results compared to DXA measurements. Lee et al. (2017) propose the prediction equations of FM for adults based on age, race, height, weight, circumference, and skinfold measurements.

Fat mass index has also been estimated by means of demographic information and components derived from the whole-body silhouettes obtained from DXA scans in children aged 6-16 years (Xie et al., 2015).

By definition, FM can also be estimated from the BFP:

$$
F M(k g)=\text { Body mass }\left(\frac{B F P}{100}\right)
$$

Fat mass index can also be calculated as:

$$
F M I\left(\frac{k g}{m^{2}}\right)=B M I-F F M I
$$

\section{Associated Health Aspects}

Fat mass index accurately classifies obesity (Peltz et al., 2010). Also, FMI seems to be a better screening tool in the prediction of the presence of metabolic syndrome than BMI and BFP in men and women (Liu et al., 2013). Furthermore, high FMI has been associated with a higher risk of mortality in the general population (Sørensen et al., 2020), although other studies did not show the impact of FMI on mortality (Graf et al., 2015).

\section{Classification Criteria}

There have been described percentiles of FMI in Caucasians for age and gender (Schutz et al., 2002). Reference intervals for FMI in Chinese adults have also been proposed for a given age and gender category (Lu et al., 2012) and by ethnicity (Jin et al., 2019). Finally, age-based reference values for FMI have been described for healthy children and adolescents from the United States (Shypailo and Wong, 2020) and adolescents from Spain (Durá-Travé et al., 2020).

\section{Limitations}

Fat mass index is age-, gender-, and ethnic-dependent. More data are necessary for children and adults. 


\section{Primary Shape and Shape Tendency}

Ratios between torso height, area, and volume that allow to estimate the type of torso (fat) volume distribution in individuals with morbid obesity, and its "intensity" or "degree."

\section{Method}

The indices are proposed by Stefan et al. (2014) and Stefan and Gilbert (2015) and are based on measurements (linear and circumferential measurements, volume, and surface data) obtained from 3D scans of torso segments in morbidly obese individuals.

Torso Volume/Surface area (TVSA) ratio

$$
\begin{aligned}
& =\frac{\text { Torso Volume }}{\text { Torso Surface Area }} \\
\text { BariPlex } & =\frac{\text { Torso Height }}{\text { TVSA ratio }} \\
\text { Superior Torso BariPlex } & =\frac{\text { Superior Torso Height }}{\text { Superior TVSA Ratio }} \\
\text { Inferior Torso BariPlex } & =\text { BariPlex }- \text { Superior Torso BariPlex } \\
\text { Primary Shape } & =\frac{\text { Superior Torso BariPlex }}{\text { BariPlex }} \\
\text { Shape Tendency } & =\frac{\text { Inferior Torso BariPlex }}{\text { Superior Torso BariPlex }}
\end{aligned}
$$

\section{Associated Health Aspects}

Primary shape allows us to identify and classify the individuals according to the obesity phenotype based on the fat distribution as "android" or "gynecoid." Android phenotype has been associated with a worse metabolic profile. It has been shown that these "shape descriptors" remain consistent throughout the weight loss. Thus, both can be used to document the measurements of preoperative morbidly obese individuals and to track their measurement changes periodically after weight loss surgery as part of the postoperative follow-up visits (Stefan and Gilbert, 2015).

\section{Classification Criteria}

A scale has been described for PS indicator for determining morbidly obese body fat distribution as gynecoid $(\geq 0.8)$, mixed (0.71-0.79), or android $(\leq 0.7)$. A scale has also been described for ST, which informs about the degree of the PS (Stefan and Gilbert, 2015).

\section{Limitations}

These indicators have been only evaluated in subjects with morbid obesity.

\section{Trunk Fat}

It is a measure of the amount of FM in the trunk (in kilograms).

\section{Method}

Trunk fat has been well-correlated with WC in children and adolescents (Taylor et al., 2000). TF has been estimated from seven skinfold measurements: triceps, biceps, chest, subscapular abdomen, thigh, and calf (He et al., 2002). Wang et al. (2003) correlated TF with WC measured at four commonly used sites in adults of both sexes. TF has also been correlated with the central obesity depth, sex, and torso volume measured by stereovision body imaging (Lee et al., 2015). Ng et al. (2016) propose a model to estimate TF in healthy adults by means of the WC, the waist width, sex, and torso volume.

Recently, Lu and Hahn (2019) have proposed a model to extrapolate $3 \mathrm{D}$ voxel-level body composition using multimodality registration based on 3D body shape derived from an optical body scan system, 2D pixel-level body composition reference derived from DXA, and a generic body composition template with anatomically accurate human skin, muscle, and skeleton system. This model shows promising results for TF distribution.

\section{Associated Health Aspects}

Trunk fat is a predictor of blood pressure in African American, Asian, and Caucasian boys at all stages of puberty ( $\mathrm{He}$ et al., 2002). Greater TF has also been associated with insulin resistance (Grunfeld et al., 2007), higher glucose levels (Snijder et al., 2004), and components of the metabolic syndrome (Wiklund et al., 2008).

\section{Classification Criteria}

Cutoffs by age and gender for identifying high TF have been proposed in children and adolescents (Taylor et al., 2000).

\section{Limitations}

There are no data for adult population.

\section{Trunk Fat percentage}

It is the percentage of FM in the trunk with respect to the total trunk mass.

\section{Method}

It is defined as the quotient between the FM in the trunk area (TF) and the total trunk mass (in the same unit).

$$
T F P=\frac{T F}{\text { Trunk mass }} 100
$$

Wang et al. (2003) correlated TFP with WC measured at four commonly used sites in adults of both sexes.

\section{Associated Health Aspects}

Trunk fat percentage is obtained from TF. Thus, we can assume that it is well-correlated with WC (Taylor et al., 2000), blood pressure (He et al., 2002), insulin resistance (Grunfeld et al., 2007), glucose levels (Snijder et al., 2004), and components of the metabolic syndrome (Wiklund et al., 2008).

\section{Classification Criteria}

Cutoffs for TFP have been proposed for high risk of inflammatory markers in children (Karatzi et al., 2016). Cutoffs for elevated risk of insulin resistance in children have also been described (Moschonis et al., 2016).

\section{Limitations}

There are no data for adult population. 


\section{A Body Shape Index}

It reports on body shape and concentration of body volume.

\section{Method}

It is an index proposed by Krakauer and Krakauer (2012) based on WC adjusted for height and weight, defined as the WC divided by the BMI raised to two-thirds and by the square root of the height.

$$
A B S I=\frac{W C}{B M I^{2 / 3} \cdot \text { Height }^{1 / 2}}
$$

\section{Associated Health Aspects}

A body shape index has been shown to be associated with adipose abdominal tissue (Krakauer and Krakauer, 2012), with components of the metabolic syndrome (Bertoli et al., 2017), cardiometabolic risk (Cheung, 2014; Fujita et al., 2015; Wang et al., 2018), and the presence (Chang et al., 2015) or onset of diabetes (He and Chen, 2013; Fujita et al., 2015; Han et al., 2017). Furthermore, ABSI was associated with carotid atherosclerosis (Geraci et al., 2019), stroke incidence in men (Abete et al., 2015), and an increased risk of CVD incident in the adult population (Bozorgmanesh et al., 2016). Finally, ABSI predicted mortality from CVD (Song et al., 2013, 2015) and was also a robust predictor of all-cause mortality (Krakauer and Krakauer, 2012; Song et al., 2015; Grant et al., 2017; Sato et al., 2017; Lee et al., 2018).

\section{Classification Criteria}

Mean values of ABSI have been described by age and gender in a large adult population (Krakauer and Krakauer, 2012).

\section{Limitations}

A body shape index depends on age and gender. There are no data for children. Furthermore, there are not specific cutoffs for clinical practice.

\section{Body Roundness Index}

An index developed by Thomas et al. (2013) attempts to quantify the individual body shape in a height-independent manner.

\section{Method}

It is a formula based on the WC and height.

$$
\begin{aligned}
B R I & =364.2-365.5 \cdot \text { Eccentricity } \\
\text { Eccentricity } & =\sqrt{1-\frac{1}{\pi^{2}}\left(\frac{W C(m)}{\text { Height }(m)}\right)^{2}}
\end{aligned}
$$

\section{Associated Health Aspects}

Body roundness index was useful to predict the insulin resistance (Feng et al., 2019) and has a good discriminatory power for metabolic syndrome in adults from diverse populations ( $\mathrm{Li}$ et al., 2019; Rico-Martín et al., 2020). BRI was also associated with the presence of diabetes mellitus (Chang et al., 2015) and higher cardiovascular risk (Maessen et al., 2014; Wang et al., 2018).

\section{Classification Criteria}

Cutoffs of BRI have been proposed in adults at high risk of cardiometabolic abnormalities (Tian et al., 2016).

\section{Limitations}

There is a lack of specific cutoffs for clinical practice. Furthermore, the complexity for the calculation of BRI compared to the simplicity of other indicators, such as BMI or WC, makes difficult the generalization of its use.

\section{Neck Circumference}

It is a relatively new, inexpensive, and practical measure to identify obesity (Ben-Noun et al., 2001; Hingorjo et al., 2012; Aswathappa et al., 2013). It is a marker of upper body subcutaneous adipose tissue distribution (Aswathappa et al., 2013).

\section{Method}

It is measured at the point just below the bulge at the thyroid cartilage (Adam's apple).

\section{Associated Health Aspects}

The NC is a simple measure that could be used to identify obesity in both adults and children (Ben-Noun et al., 2001; Hingorjo et al., 2012; Lou et al., 2012). The NC is also associated with other anthropometric measures for obesity and body distribution (Preis et al., 2010). Furthermore, some studies have indicated that NC could be considered as an independent correlate of cardiometabolic risk factors (Ben-Noun and Laor, 2003, 2004, 2006; Preis et al., 2010; Guo et al., 2012).

\section{Classification Criteria}

Different cutoffs for NC have been proposed to identify subjects with overweight/obesity (Ben-Noun et al., 2001; Hingorjo et al., 2012). However, there are not enough data to establish the utility of these cutoffs.

\section{Limitations}

There is a lack of specific cutoffs for clinical practice.

\section{DISCUSSION}

Obesity is one of the most prevalent metabolic disorders worldwide, which is a known risk factor for non-communicable diseases: metabolic syndrome, type 2 diabetes, CV disease, arthrosis, cancer, and depression. Obesity has a high impact on metabolic disturbances, contributing to the development of insulin resistance, atherogenic dyslipidemia, metabolic syndrome, and non-alcoholic fatty liver disease, leading to the development of type 2 diabetes and cardiovascular disease. However, not all obese subjects develop metabolic complications (Smith et al., 2019).Therefore, it is important to detect those most at risk. In this sense, the AHI have become a fundamental tool for the identification, intervention, or evaluation of the impact of risks. This study identified and analyzed 17 AHIs that can be obtained or estimated from 3D human shapes.

Among the 17 AHIs, the main ones used in the literature for their estimation are shown in Table 1. Measuring tapes have traditionally been used for circumferences and lengths. For volume measurements, air and water displacement techniques have been commonly used to estimate the total body volume. Other techniques such as CT or MRI are useful to assess the total 
and regional body volume. However, all of these techniques are invasive in one way or another, require well-trained laboratory personnel, and are far too expensive for field settings, making obtaining AHI not very accessible for an extensive diagnosis of obesity and other health risk factors.

In this sense, studies that use traditional techniques have been complemented or replaced by studies that use 3D imaging devices and other emerging, inexpensive, and accessible technologies that make obtaining body dimensions easy and reliable (Medina-Inojosa et al., 2016; Ballester et al., 2018). The body measurements obtained with these new technologies have been correlated with reference methods ( $\mathrm{Ng}$ et al., 2016; Bourgeois et al., 2017; Tinsley et al., 2020). In addition, these novel technologies have opened a way to evaluate other body parameters such as surface areas or AHIs shape descriptors (Stefan et al., 2014; Lu et al., 2018), whose application has even been improved by machine learning techniques (Harty et al., 2020).

From the 17 AHIs evaluated, those with the most published references on the subject covered by our review were BMI, WC, BFP, VATA, SAD, FFMI, FMI, ABSI, and BRI. However, until now, none of the AHIs is considered a sufficiently accurate method for the assessment of body composition in obesity. All of them have shown advantages and limitations. The AHIs most widely used in clinical practice are BMI and WC. In fact, the definition of obesity is based on BMI cutoffs. BMI is readily available, and there are the well-established cutoffs for the population. It is useful to estimate the overall body fat; however, it is not appropriate to evaluate the visceral fat or fat distribution (Ashwell et al., 2012; Böhm and Heitmann, 2013; Britton et al., 2013). Other AHIs such as WC or those that include waist measurement are well-correlated with visceral fat (Lemieux et al., 1996; Ashwell et al., 2012) being also used routinely in clinical practice. However, these are also imperfect as indicators of intra-abdominal fat because they also include subcutaneous fat deposition. On the contrary, there are AHIs that provide more information on the distribution of body fat, but it is necessary to use complex, invasive, and/or expensive techniques (BIA, DXA, CT, etc.) to obtain them (Duren et al., 2008). Therefore, they are unsuitable for clinical practice. On the other hand, in addition to the inherent limitations of any individual AHI, only BMI, WC, and WHR offer the well-established cutoff values for classifying patients. In fact, the cutoff values for the rest of AHIs are not yet validated. Furthermore, universal cutoffs may not be applicable to certain ethnic groups. In recent years, interest has focused on estimating or predicting these AHIs from 3D scanning systems through a novel set of measurements (Giachetti et al., 2015), integrating perceptual-level geometry characteristics to regression equations (Lu et al., 2018), using multimodal registration (Lu and Hahn, 2019), or statistical modeling of shapes (Ng et al., 2019), and in the evaluation of the validity of the AHIs using reference methods (Ryder, 2010; Adler et al., 2017; Harbin et al., 2018; Wong et al., 2019; Tinsley et al., 2020). 3D scanning systems could easily help identify the regional distribution of fat, which in fact critically determines the overall effects of obesity on health risks.
The studies reviewed have demonstrated the potential of 3D imaging techniques and other emerging technologies to estimate AHIs, particularly those related to body composition, which are now on the rise due to their usefulness. However, they reflect that the predictive equations of body composition still need to be refined to be considered an accurate method. Additionally, only a few AHIs have widely accepted cutoffs that can be used routinely to assist the clinician. Finally, the present study has some limitations. Interesting articles may be missing from the scope of our review because we have analyzed articles found in PubMed but not manuscripts included in other databases. In addition, we have carried out the bibliographic search with a limiting title and/or abstract field. Future work may also target AHIs of Categories 2, 3, and 4 for 3D body shape estimates or extended classification criteria.

\section{CONCLUSION}

This review provides an overview of all AHIs, with particular emphasis on those that can be obtained or estimated from 3D human shapes, due to the rise and potential of 3D scanning systems. 3D scanning systems and other emerging technologies can play an important role in the prevention and early detection of obesity and other health risk factors, due, among other aspects, to their accessibility, and can even be used in primary care.

Our findings reveal that although many AHIs have emerged, until now there is no single method sufficiently adequate for the estimation of adiposity and its distribution and, therefore, for the evaluation of obesity and other risk factors for health. Future studies are still needed to improve body composition prediction methods, with widely accepted cutoff points for clinical practice, and for the study of AHIs of Categories 2, 3, and 4 to convert them into Category 1.

\section{AUTHOR CONTRIBUTIONS}

PP, JD-G, AB, and SM-H conceptualized and structured the manuscript, performed the general search, review, selection, and classification of the references. PP and SM-H wrote the manuscript. PP, SM-H, AB, JRea, and JRed participated in the manuscript editing and revised it for important intellectual content. All authors have reviewed and approved the final manuscript.

\section{FUNDING}

BODYPASS Project has received funding from the European Union's Horizon 2020 research and innovation program under Grant Agreement No. 779780. CIBER de Diabetes and Enfermedades Metabólicas Asociadas (CIBERDEM) is an Instituto de Salud Carlos III initiative. SM-H was an investigator in the Juan Rodes program (JR18/00051) financed by the Instituto de Salud Carlos III and the European Regional Development Fund (FEDER). Project (IMDEEA/2020/87) supported by Instituto Valenciano de 
Competitividad Empresarial (IVACE), call for proposals 2020 for Technology Centers of the Comunitat Valenciana, cofunded by ERDF Funds, EU Operational Program of the Comunitat Valenciana 2014-2020.

\section{REFERENCES}

Abete, I., Arriola, L., Etxezarreta, N., Mozo, I., Moreno-Iribas, C., Amiano, P., et al. (2015). Association between different obesity measures and the risk of stroke in the EPIC Spanish cohort. Eur. J. Nutr. 54, 365-375. doi: 10.1007/s00394-014-0716-x

Adler, C., Steinbrecher, A., Jaeschke, L., Mähler, A., Boschmann, M., Jeran, S., et al. (2017). Validity and reliability of total body volume and relative body fat mass from a 3-dimensional photonic body surface scanner. PLoS ONE 12:e180201. doi: 10.1371/journal.pone.0180201

Alberti, K. G. M. M., Zimmet, P., and Shaw, J. (2006). Metabolic syndromea new world-wide definition. a consensus statement from the international diabetes federation. Diabet. Med. J. Br. Diabet. Assoc. 23, 469-480. doi: 10.1111/j.1464-5491.2006.01858.x

Al-Daghri, N., Alokail, M., Al-Attas, O., Sabico, S., and Kumar, S. (2010). Establishing abdominal height cut-offs and their association with conventional indices of obesity among Arab children and adolescents. Ann. Saudi Med. 30, 209-214. doi: 10.4103/0256-4947.62835

Almeida, R. T., de Almeida, M. M. G., and de Araújo, T. M. (2009). Abdominal obesity and cardiovascular risk: performance of anthropometric indexes in women. Arq. Bras. Cardiol. 92, 345-350. doi: 10.1590/S0066-782X2009000500007

Andrade, M. D., Freitas, M. C. P., de Sakumoto, A. M., Pappiani, C., Andrade, S. C., de Vieira, V. L., et al. (2016). Association of the conicity index with diabetes and hypertension in Brazilian women. Arch. Endocrinol. Metab. 60, 436-442. doi: 10.1590/2359-3997000000187

Aranceta-Bartrina, J., Pérez-Rodrigo, C., Alberdi-Aresti, G., Ramos-Carrera, N., and Lázaro-Masedo, S. (2016). Prevalence of general obesity and abdominal obesity in the spanish adult population (aged 25-64 years) 2014-2015: The ENPE study. Rev. Esp. Cardiol. Engl. Ed. 69, 579-587. doi: 10.1016/j.recesp.2016.02.010

Ashwell, M., Gunn, P., and Gibson, S. (2012). Waist-to-height ratio is a better screening tool than waist circumference and BMI for adult cardiometabolic risk factors: systematic review and meta-analysis. Obes. Rev. Off. J. Int. Assoc. Study Obes. 13, 275-286. doi: 10.1111/j.1467-789X.2011.00952.x

Ashwell, M., Mayhew, L., Richardson, J., and Rickayzen, B. (2014). Waist-to-height ratio is more predictive of years of life lost than body mass index. PLoS ONE 9:e103483. doi: 10.1371/journal.pone.0103483

Aswathappa, J., Garg, S., Kutty, K., and Shankar, V. (2013). Neck circumference as an anthropometric measure of obesity in diabetics. North Am. J. Med. Sci. 5, 28-31. doi: 10.4103/1947-2714.106188

Aune, D., Sen, A., Prasad, M., Norat, T., Janszky, I., Tonstad, S., et al. (2016). $\mathrm{BMI}$ and all cause mortality: systematic review and non-linear dose-response meta-analysis of 230 cohort studies with 3.74 million deaths among 30.3 million participants. BMJ 353:i2156. doi: 10.1136/bmj.i2156

Balkau, B., and Charles, M. A. (1999). Comment on the provisional report from the WHO consultation. European group for the study of insulin resistance (EGIR). Diabet. Med. J. Br. Diabet. Assoc. 16, 442-443. doi: 10.1046/j.1464-5491.1999.00059.x

Ballester, A., Pierola, A., Parrilla, E., Uriel, J., Ruescas, A. V., Pérez, C., et al. (2018). 3 D Human Models From 1 D, 2 D \& 3 D Inputs: Reliability and Compatibility of Body Measurements. Available online at: https://www.semanticscholar.org/ paper/3-D-Human-Models-from-1-D-\%2C-2-D-\%26-3-D-Inputs-\%3Aand-Ballester-Pi\%C3\%A9rola/7e6891d700af86fd6177fb2ade6b066ca5688478 (accessed October 27, 2020).

Barlett, H. L., Puhl, S. M., Hodgson, J. L., and Buskirk, E. R. (1991). Fat-free mass in relation to stature: ratios of fat-free mass to height in children, adults, and elderly subjects. Am. J. Clin. Nutr. 53, 1112-1116. doi: 10.1093/ajcn/53.5.1112

Ben-Noun, L., and Laor, A. (2003). Relationship of neck circumference to cardiovascular risk factors. Obes. Res. 11, 226-231. doi: 10.1038/oby.2003.35

Ben-Noun, L., Sohar, E., and Laor, A. (2001). Neck circumference as a simple screening measure for identifying overweight and obese patients. Obes. Res. 9, 470-477. doi: 10.1038/oby.2001.61
Ben-Noun, L. L., and Laor, A. (2004). Relationship between changes in neck circumference and changes in blood pressure. Am. J. Hypertens. 17, 409-414. doi: 10.1016/j.amjhyper.2004.02.005

Ben-Noun, L. L., and Laor, A. (2006). Relationship between changes in neck circumference and cardiovascular risk factors. Exp. Clin. Cardiol. 11, 14-20.

Bergman, R. N., Stefanovski, D., Buchanan, T. A., Sumner, A. E., Reynolds, J. C., Sebring, N. G., et al. (2011). A better index of body adiposity. Obesity 19, 1083-1089. doi: 10.1038/oby.2011.38

Bertoli, S., Leone, A., Krakauer, N. Y., Bedogni, G., Vanzulli, A., Redaelli, V. I., et al. (2017). Association of body shape index (ABSI) with cardio-metabolic risk factors: A cross-sectional study of 6081 Caucasian adults. PLoS ONE 12:e0185013. doi: 10.1371/journal.pone. 0185013

Blüher, M. (2019). Obesity: global epidemiology and pathogenesis. Nat. Rev. Endocrinol. 15, 288-298. doi: 10.1038/s41574-019-0176-8

Böhm, A., and Heitmann, B. L. (2013). The use of bioelectrical impedance analysis for body composition in epidemiological studies. Eur. J. Clin. Nutr. 67(Suppl. 1), S79-85. doi: 10.1038/ejcn.2012.168

Bourgeois, B., Ng, B. K., Latimer, D., Stannard, C. R., Romeo, L., Li, X., et al. (2017). Clinically applicable optical imaging technology for body size and shape analysis: comparison of systems differing in design. Eur. J. Clin. Nutr. 71, 1329-1335. doi: 10.1038/ejcn.2017.142

Bozorgmanesh, M., Sardarinia, M., Hajsheikholeslami, F., Azizi, F., and Hadaegh, F. (2016). CVD-predictive performances of "a body shape index" versus simple anthropometric measures: tehran lipid and glucose study. Eur. J. Nutr. 55, 147-157. doi: 10.1007/s00394-015-0833-1

Brambilla, P., Bedogni, G., Moreno, L. A., Goran, M. I., Gutin, B., Fox, K. R., et al. (2006). Crossvalidation of anthropometry against magnetic resonance imaging for the assessment of visceral and subcutaneous adipose tissue in children. Int. J. Obes. 30, 23-30. doi: 10.1038/sj.ijo.0803163

Bray, G. A., Frühbeck, G., Ryan, D. H., and Wilding, J. P. H. (2016). Management of obesity. Lancet 387, 1947-1956. doi: 10.1016/S0140-6736(16)00271-3

Britton, K. A., Massaro, J. M., Murabito, J. M., Kreger, B. E., Hoffmann, U., and Fox, C. S. (2013). Body fat distribution, incident cardiovascular disease, cancer, and all-cause mortality. J. Am. Coll. Cardiol. 62, 921-925. doi: 10.1016/j.jacc.2013.06.027

Browning, L. M., Hsieh, S. D., and Ashwell, M. (2010). A systematic review of waistto-height ratio as a screening tool for the prediction of cardiovascular disease and diabetes: 0.5 could be a suitable global boundary value. Nutr. Res. Rev. 23, 247-269. doi: 10.1017/S0954422410000144

BroŽek, J., Grande, F., Anderson, J. T., and Keys, A. (1963). Densitometric analysis of body composition: revision of some quantitative assumptions*. Ann. N. Y. Acad. Sci. 110, 113-140. doi: 10.1111/j.1749-6632.1963.tb17079.x

Cai, L., Liu, A., Zhang, Y., and Wang, P. (2013). Waist-to-height ratio and cardiovascular risk factors among Chinese adults in Beijing. PLoS ONE 8:e69298. doi: 10.1371/journal.pone.0069298

Campbell, T. M., and Vallis, L. A. (2014). Predicting fat-free mass index and sarcopenia in assisted-living older adults. AGE 36:9674. doi: 10.1007/s11357-014-9674-8

Carey, V. J., Walters, E. E., Colditz, G. A., Solomon, C. G., Willett, W. C., Rosner, B. A., et al. (1997). Body fat distribution and risk of non-insulin-dependent diabetes mellitus in women. the Nurses' Health Study. Am. J. Epidemiol. 145, 614-619. doi: 10.1093/oxfordjournals.aje.a009158

Carletti, M., Cristani, M., Cavedon, V., Milanese, C., Zancanaro, C., and Giachetti, A. (2018). "Estimating body fat from depth images: hand-crafted features vs convolutional neural networks," in Proceedings of 3DBODY.TECH 2018 - 9th International Conference and Exhibition on 3D Body Scanning and Processing Technologies, Lugano, Switzerland, 16-17 Oct. 2018 (Lugano: Hometrica Consulting - Dr. Nicola D’Apuzzo), 201-206. doi: 10.15221/18.201

Ceolin, J., Engroff, P., Mattiello, R., and Schwanke, C. H. A. (2019). Performance of anthropometric indicators in the prediction of metabolic syndrome in the elderly. Metab. Syndr. Relat. Disord. 17, 232-239. doi: 10.1089/met.2018.0113

Cerhan, J. R., Moore, S. C., Jacobs, E. J., Kitahara, C. M., Rosenberg, P. S., Adami, H.-O., et al. (2014). A pooled analysis of waist circumference 
and mortality in 650,000 adults. Mayo Clin. Proc. 89, 335-345. doi: 10.1016/j.mayocp.2013.11.011

Chan, J. M., Rimm, E. B., Colditz, G. A., Stampfer, M. J., and Willett, W. C. (1994). Obesity, fat distribution, and weight gain as risk factors for clinical diabetes in men. Diabetes Care 17, 961-969. doi: 10.2337/diacare. 17.9.961

Chang, Y., Guo, X., Chen, Y., Guo, L., Li, Z., Yu, S., et al. (2015). A body shape index and body roundness index: two new body indices to identify diabetes mellitus among rural populations in northeast China. BMC Public Health 15:794. doi: 10.1186/s12889-015-2150-2

Cheung, Y. B. (2014). "A Body Shape Index" in middle-age and older Indonesian population: scaling exponents and association with incident hypertension. PLoS ONE 9:e85421. doi: 10.1371/journal.pone.0085421

Clasey, J. L., Bouchard, C., Teates, C. D., Riblett, J. E., Thorner, M. O., Hartman, M. L., et al. (1999). The use of anthropometric and dualenergy X-ray absorptiometry (DXA) measures to estimate total abdominal and abdominal visceral fat in men and women. Obes. Res. 7, 256-264. doi: 10.1002/j.1550-8528.1999.tb00404.x

Cole, T. J., Bellizzi, M. C., Flegal, K. M., and Dietz, W. H. (2000). Establishing a standard definition for child overweight and obesity worldwide: international survey. BMJ 320, 1240-1243. doi: 10.1136/bmj.320. 7244.1240

Cole, T. J., Flegal, K. M., Nicholls, D., and Jackson, A. A. (2007). Body mass index cut offs to define thinness in children and adolescents: international survey. BMJ 335:194. doi: 10.1136/bmj.39238.399444.55

Cook, S., Weitzman, M., Auinger, P., Nguyen, M., and Dietz, W. H. (2003). Prevalence of a metabolic syndrome phenotype in adolescents: findings from the third National Health and Nutrition Examination Survey, 19881994. Arch. Pediatr. Adolesc. Med. 157, 821-827. doi: 10.1001/archpedi.157. 8.821

Cristine Silva, K., Santana Paiva, N., Rocha de Faria, F., Franceschini, S., do C. C., and Eloiza Piore, S. (2020). Predictive ability of seven anthropometric indices for cardiovascular risk markers and metabolic syndrome in adolescents. J. Adolesc. Health Off. Publ. Soc. Adolesc. Med. 66, 491-498. doi: 10.1016/j.jadohealth.2019.10.021

Dalton, M., Cameron, A. J., Zimmet, P. Z., Shaw, J. E., Jolley, D., Dunstan, D. W., et al. (2003). Waist circumference, waist-hip ratio and body mass index and their correlation with cardiovascular disease risk factors in Australian adults. $J$. Intern. Med. 254, 555-563. doi: 10.1111/j.1365-2796.2003.01229.x

de Souza, N. C., and de Oliveira, E. P. (2013). Sagittal abdominal diameter shows better correlation with cardiovascular risk factors than waist circumference and BMI. J. Diabetes Metab. Disord. 12:41. doi: 10.1186/2251-6581-12-41

Dervaux, N., Wubuli, M., Megnien, J.-L., Chironi, G., and Simon, A. (2008). Comparative associations of adiposity measures with cardiometabolic risk burden in asymptomatic subjects. Atherosclerosis 201, 413-417. doi: 10.1016/j.atherosclerosis.2007.11.032

Deurenberg, P., and Deurenberg-Yap, M. (2003). Validity of body composition methods across ethnic population groups. Acta Diabetol. 40(Suppl. 1), S246S249. doi: 10.1007/s00592-003-0077-z

Deurenberg, P., Pieters, J. J. L., and Hautvast, J. G. A. J. (1990). The assessment of the body fat percentage by skinfold thickness measurements in childhood and young adolescence. Br. J. Nutr. 63, 293-303. doi: 10.1079/BJN19900116

Deurenberg, P., Weststrate, J. A., and Seidell, J. C. (1991). Body mass index as a measure of body fatness: age- and sex-specific prediction formulas. Br. J. Nutr. 65, 105-114. doi: 10.1079/BJN19910073

Di Angelantonio, E., Bhupathiraju, S. N., Wormser, D., Gao, P., Kaptoge, S., de Gonzalez, A. B., et al. (2016). Body-mass index and all-cause mortality: individual-participant-data meta-analysis of 239 prospective studies in four continents. Lancet 388, 776-786. doi: 10.1016/S0140-6736(16)30175-1

Dobbelsteyn, C. J., Joffres, M. R., MacLean, D. R., and Flowerdew, G. (2001). A comparative evaluation of waist circumference, waist-to-hip ratio and body mass index as indicators of cardiovascular risk factors. The Canadian heart health surveys. Int. J. Obes. Relat. Metab. Disord. J. Int. Assoc. Study Obes. 25, 652-661. doi: 10.1038/sj.ijo.0801582

Durá-Travé, T., Gallinas-Victoriano, F., Malumbres Chacón, M., Moreno González, P., Ahmed-Mohamed, L., and Urretavizcaya-Martínez, M. (2020). Reference values of fat mass index and fat-free mass index in healthy Spanish adolescents. Nutr. Hosp. 37, 902-908. doi: 10.20960/nh.03161
Duren, D. L., Sherwood, R. J., Czerwinski, S. A., Lee, M., Choh, A. C., Siervogel, R. M., et al. (2008). Body composition methods: comparisons and interpretation. J. Diabetes Sci. Technol. 2, 1139-1146. doi: 10.1177/193229680800200623

Durnin, J. V. G. A., and Womersley, J. (1974). Body fat assessed from total body density and its estimation from skinfold thickness: measurements on 481 men and women aged from 16 to 72 Years. Br. J. Nutr. 32, 77-97. doi: 10.1079/BJN19740060

Dwivedi, A. K., Dubey, P., Cistola, D. P., and Reddy, S. Y. (2020). Association between obesity and cardiovascular outcomes: updated evidence from metaanalysis studies. Curr. Cardiol. Rep. 22:25. doi: 10.1007/s11886-020-1273-y

Ehrampoush, E., Arasteh, P., Homayounfar, R., Cheraghpour, M., Alipour, M., Naghizadeh, M. M., et al. (2017). New anthropometric indices or old ones: Which is the better predictor of body fat? Diabetes Metab. Syndr. 11, 257-263. doi: 10.1016/j.dsx.2016.08.027

Empana, J. P., Ducimetiere, P., Charles, M. A., and Jouven, X. (2004). Sagittal abdominal diameter and risk of sudden death in asymptomatic middle-aged men: the paris prospective study I. Circulation 110, 2781-2785. doi: 10.1161/01.CIR.0000146395.64065.BA

Escobedo-de la Peña, J., Ramírez-Hernández, J. A., Fernández-Ramos, M. T., González-Figueroa, E., and Champagne, B. (2020). Body fat percentage rather than body mass index related to the high occurrence of type 2 diabetes. Arch. Med. Res. 51, 564-571. doi: 10.1016/j.arcmed.2020.05.010

Expert Panel on Detection, Evaluation and Treatment of High Blood Cholesterol in Adults (2001). Executive summary of the third report of the national cholesterol education program (NCEP) expert panel on detection, evaluation, and treatment of high blood cholesterol in adults (adult treatment panel III). JAMA 285, 2486-2497. doi: 10.1001/jama.285.19.2486

Farina, G. L., Spataro, F., De Lorenzo, A., and Lukaski, H. (2016). A smartphone application for personal assessments of body composition and phenotyping. Sensors 16:2163. doi: 10.3390/s16122163

Feng, J., He, S., and Chen, X. (2019). Body adiposity index and body roundness index in identifying insulin resistance among adults without diabetes. Am. J. Med. Sci. 357, 116-123. doi: 10.1016/j.amjms.2018.11.006

Filgueiras, M. D. S., Vieira, S. A., Fonseca, P. C., de, A., Pereira, P. F., Ribeiro, A. Q., et al. (2019). Waist circumference, waist-to-height ratio and conicity index to evaluate android fat excess in Brazilian children. Public Health Nutr. 22, 140-146. doi: $10.1017 /$ S1368980018002483

Firouzi, S. A., Tucker, L. A., LeCheminant, J. D., and Bailey, B. W. (2018). Sagittal abdominal diameter, waist circumference, and BMI as predictors of multiple measures of glucose metabolism: An NHANES investigation of US adults. J. Diabetes Res. 2018:e3604108. doi: 10.1155/2018/3604108

Ford, E. S., Williamson, D. F., and Liu, S. (1997). Weight change and diabetes incidence: findings from a national cohort of US adults. Am. J. Epidemiol. 146, 214-222. doi: 10.1093/oxfordjournals.aje.a009256

Fujita, M., Sato, Y., Nagashima, K., Takahashi, S., and Hata, A. (2015). Predictive power of a body shape index for development of diabetes, hypertension, and dyslipidemia in Japanese adults: a retrospective cohort study. PLoS ONE 10:e0128972. doi: 10.1371/journal.pone.0128972

Gadelha, A. B., Myers, J., Moreira, S., Dutra, M. T., Safons, M. P., and Lima, R. M. (2016). Comparison of adiposity indices and cut-off values in the prediction of metabolic syndrome in postmenopausal women. Diabetes Metab. Syndr. 10, 143-148. doi: 10.1016/j.dsx.2016.01.005

Gallagher, D., Heymsfield, S. B., Heo, M., Jebb, S. A., Murgatroyd, P. R., and Sakamoto, Y. (2000). Healthy percentage body fat ranges: an approach for developing guidelines based on body mass index. Am. J. Clin. Nutr. 72, 694-701. doi: $10.1093 / \mathrm{ajcn} / 72.3 .694$

Geraci, G., Zammuto, M., Gaetani, R., Mattina, A., D'Ignoto, F., Geraci, C., et al. (2019). Relationship of a body shape index and body roundness index with carotid atherosclerosis in arterial hypertension. Nutr. Metab. Cardiovasc. Dis. NMCD 29, 822-829. doi: 10.1016/j.numecd.2019.04.013

Giachetti, A., Lovato, C., Piscitelli, F., Milanese, C., and Zancanaro, C. (2015). Robust automatic measurement of $3 \mathrm{~d}$ scanned models for the human body fat estimation. IEEE J. Biomed. Health Inform. 19, 660-667. doi: 10.1109/JBHI.2014.2314360

Gletsu-Miller, N., Kahn, H. S., Gasevic, D., Liang, Z., Frediani, J. K., Torres, W. E., et al. (2013). Sagittal abdominal diameter and visceral adiposity: correlates of beta-cell function and dysglycemia in severely obese women. Obes. Surg. 23, 874-881. doi: 10.1007/s11695-013-0874-6 
Gómez-Ambrosi, J., Silva, C., Catalán, V., Rodríguez, A., Galofré, J. C., Escalada, J., et al. (2012). Clinical usefulness of a new equation for estimating body fat. Diabetes Care 35, 383-388. doi: 10.2337/dc11-1334

Gómez-Ambrosi, J., Silva, C., Galofr,é, J. C., Escalada, J., Santos, S., Gil, M. J., et al. (2011). Body adiposity and type 2 diabetes: increased risk with a high body fat percentage even having a normal BMI. Obes. Silver Spring Md 19, 1439-1444. doi: 10.1038 /oby.2011.36

Graf, C. E., Karsegard, V. L., Spoerri, A., Makhlouf, A.-M., Ho, S., Herrmann, F. R., et al. (2015). Body composition and all-cause mortality in subjects older than 65 y. Am. J. Clin. Nutr. 101, 760-767. doi: 10.3945/ajcn.114.102566

Grant, J. F., Chittleborough, C. R., Shi, Z., and Taylor, A. W. (2017). The association between A body shape index and mortality: results from an Australian cohort. PLOS ONE 12:e0181244. doi: 10.1371/journal.pone. 0181244

Grunfeld, C., Rimland, D., Gibert, C. L., Powderly, W. G., Sidney, S., Shlipak, M. G., et al. (2007). Association of upper trunk and visceral adipose tissue volume with insulin resistance in control and HIV-infected subjects in the FRAM study. J. Acquir. Immune Defic. Syndr. 46, 283-290. doi: 10.1097/QAI.0b013e31814b94e2

Guerrero-Romero, F., and Rodríguez-Morán, M. (2003). Abdominal volume index. an anthropometry-based index for estimation of obesity is strongly related to impaired glucose tolerance and type 2 diabetes mellitus. Arch. Med. Res. 34, 428-432. doi: 10.1016/S0188-4409(03)00073-0

Guo, X., Li, Y., Sun, G., Yang, Y., Zheng, L., Zhang, X., et al. (2012). Prehypertension in children and adolescents: association with body weight and neck circumference. Intern. Med. Tokyo Jpn. 51, 23-27. doi: 10.2169/internalmedicine.51.6347

Gustat, J., Elkasabany, A., Srinivasan, S., and Berenson, G. S. (2000). Relation of abdominal height to cardiovascular risk factors in young adults: the Bogalusa heart study. Am. J. Epidemiol. 151, 885-891. doi: 10.1093/oxfordjournals.aje.a010292

Guzzaloni, G., Minocci, A., Marzullo, P., and Liuzzi, A. (2009). Sagittal abdominal diameter is more predictive of cardiovascular risk than abdominal fat compartments in severe obesity. Int. J. Obes. 33, 233-238. doi: 10.1038/ijo.2008.271

Han, C., Liu, Y., Sun, X., Luo, X., Zhang, L., Wang, B., et al. (2017). Prediction of a new body shape index and body adiposity estimator for development of type 2 diabetes mellitus: the rural chinese cohort study. Br. J. Nutr. 118, 771-776. doi: 10.1017/S0007114517002859

Han, T. S., van Leer, E. M., Seidell, J. C., and Lean, M. E. (1995). Waist circumference action levels in the identification of cardiovascular risk factors: prevalence study in a random sample. BMJ 311, 1401-1405. doi: 10.1136/bmj.311.7017.1401

Harbin, M. M., Kasak, A., Ostrem, J. D., and Dengel, D. R. (2018). Validation of a three-dimensional body scanner for body composition measures. Eur. J. Clin. Nutr. 72, 1191-1194. doi: 10.1038/s41430-017-0046-1

Harty, P. S., Sieglinger, B., Heymsfield, S. B., Shepherd, J. A., Bruner, D., Stratton, M. T., et al. (2020). Novel body fat estimation using machine learning and 3-dimensional optical imaging. Eur. J. Clin. Nutr. 74, 842-845. doi: 10.1038/s41430-020-0603-X

He, Q., Horlick, M., Fedun, B., Wang, J., Pierson, R. N., Heshka, S., et al. (2002). Trunk fat and blood pressure in children through puberty. Circulation 105, 1093-1098. doi: 10.1161/hc0902.104706

He, S., and Chen, X. (2013). Could the new body shape index predict the new onset of diabetes mellitus in the Chinese population? PLOS ONE 8:e50573. doi: 10.1371/journal.pone.0050573

Heo, M., Kabat, G. C., Gallagher, D., Heymsfield, S. B., and Rohan, T. E. (2013). Optimal scaling of weight and waist circumference to height for maximal association with DXA-measured total body fat mass by sex, age and race/ethnicity. Int. J. Obes. 37, 1154-1160. doi: 10.1038/ijo.2012.201

Hernández-Vásquez, A., Azañedo, D., Vargas-Fernández, R., Aparco, J. P., Chaparro, R. M., and Santero, M. (2020). Cut-off pointds of anthropometric markers associated with hypertension and diabetes in Peru: Demographic and Health Survey 2018. Public Health Nutr. 16, 1-30. doi: $10.1017 /$ S1368980020004036

Hingorjo, M. R., Qureshi, M. A., and Mehdi, A. (2012). Neck circumference as a useful marker of obesity: a comparison with body mass index and waist circumference. JPMA J. Pak. Med. Assoc. 62, 36-40.
Hu, C., Chen, X., Yao, C., Liu, Y., Xu, H., Zhou, G., et al. (2020). Body mass indexassociated molecular characteristics involved in tumor immune and metabolic pathways. Cancer Metab. 8:21. doi: 10.1186/s40170-020-00225-6

Hull, H. R., Thornton, J., Wang, J., Pierson, R. N., Kaleem, Z., Pi-Sunyer, X., et al. (2011). Fat-free mass index: changes and race/ethnic differences in adulthood. Int. J. Obes. 35, 121-127. doi: 10.1038/ijo.2010.111

Iribarren, C., Darbinian, J. A., Lo, J. C., Fireman, B. H., and Go, A. S. (2006) Value of the sagittal abdominal diameter in coronary heart disease risk assessment: cohort study in a large, multiethnic population. Am. J. Epidemiol. 164, 1150-1159. doi: 10.1093/aje/kwj341

Jackson, A. S., and Pollock, M. L. (1978). Generalized equations for predicting body density of men. Br. J. Nutr. 40, 497-504. doi: 10.1079/BJN19780152

Jackson, A. S., Pollock, M. L., and Ward, A. (1980). Generalized equations for predicting body density of women. Med. Sci. Sports Exerc. 12, 175-181. doi: 10.1249/00005768-198023000-00009

Jia, A., Xu, S., Ming, J., Xing, Y., Guo, J., Zhao, M., et al. (2018). Body fat percentage cutoffs for risk of cardiometabolic abnormalities in the Chinese adult population: a nationwide study. Eur. J. Clin. Nutr. 72, 728-735. doi: 10.1038/s41430-018-0107-0

Jin, M., Du, H., Zhang, Y., Zhu, H., Xu, K., Yuan, X., et al. (2019). Characteristics and reference values of fat mass index and fat free mass index by bioelectrical impedance analysis in an adult population. Clin. Nutr. Edinb. Scotl. 38, 2325-2332. doi: 10.1016/j.clnu.2018.10.010

Kahn, C. R., Wang, G., and Lee, K. Y. (2019). Altered adipose tissue and adipocyte function in the pathogenesis of metabolic syndrome. J. Clin. Invest. 129, 3990-4000. doi: 10.1172/JCI129187

Kahn, H. S., Austin, H., Williamson, D. F., and Arensberg, D. (1996a). Simple anthropometric indices associated with ischemic heart disease. J. Clin. Epidemiol. 49, 1017-1024. doi: 10.1016/0895-4356(96)00113-8

Kahn, H. S., Gu, Q., Bullard, K. M., Freedman, D. S., Ahluwalia, N., and Ogden, C. L. (2014). Population distribution of the sagittal abdominal diameter (SAD) from a representative sample of US adults: comparison of SAD, waist circumference and body mass index for identifying dysglycemia. PLoS ONE 9:e108707. doi: 10.1371/journal.pone.0108707

Kahn, H. S., Simoes, E. J., Koponen, M., and Hanzlick, R. (1996b). The abdominal diameter index and sudden coronary death in men. Am. J. Cardiol. 78, 961-964. doi: 10.1016/S0002-9149(96)00479-1

Kahn, H. S., and Williamson, D. F. (1993). Sagittal abdominal diameter. Int. J. Obes. Relat. Metab. Disord. J. Int. Assoc. Study Obes. 17:669.

Kang, S. J., Kim, D., Park, H. E., Choi, S. H., Choi, S.-Y., Lee, W., et al. (2014). Visceral adipose tissue area is associated with coronary stenosis and noncalcified plaques. Int. J. Obes. 38, 272-278. doi: 10.1038/ijo.2013.105

Karatzi, K., Moschonis, G., Polychronopoulou, M. C., Chrousos, G. P., Lionis, C., Manios, Y., et al. (2016). Cutoff points of waist circumference and trunk and visceral fat for identifying children with elevated inflammation markers and adipokines: The healthy growth study. Nutr. Burbank Los Angel. Cty. Calif 32, 1063-1067. doi: 10.1016/j.nut.2016.02.022

Katzmarzyk, P. T., Heymsfield, S. B., and Bouchard, C. (2013). Clinical utility of visceral adipose tissue for the identification of cardiometabolic risk in white and African American adults. Am. J. Clin. Nutr. 97, 480-486. doi: 10.3945/ajcn.112.047787

Kim, J. A., Choi, C. J., and Yum, K. S. (2006). Cut-off values of visceral fat area and waist circumference: diagnostic criteria for abdominal obesity in a Korean population. J. Korean Med. Sci. 21, 1048-1053. doi: 10.3346/jkms.2006.21.6.1048

Kim, J. Y., Han, S.-H., and Yang, B.-M. (2013). Implication of high-body-fat percentage on cardiometabolic risk in middle-aged, healthy, normal-weight adults. Obes. Silver Spring Md 21, 1571-1577. doi: 10.1002/oby.20020

Kim, K. S., Owen, W. L., Williams, D., and Adams-Campbell, L. L. (2000). A comparison between BMI and conicity index on predicting coronary heart disease: the Framingham heart study. Ann. Epidemiol. 10, 424-431. doi: 10.1016/S1047-2797(00)00065-X

Krakauer, N. Y., and Krakauer, J. C. (2012). A new body shape index predicts mortality hazard independently of body mass index. PLOS ONE 7:e39504. doi: 10.1371/journal.pone.0039504

Kudsk, K. A., Munoz-Del-Rio, A., Busch, R. A., Kight, C. E., and Schoeller, D. A. (2017). Stratification of fat-free mass index percentiles for body composition based on national health and nutrition examination survey III 
bioelectric impedance data. JPEN J. Parenter. Enteral Nutr. 41, 249-257. doi: $10.1177 / 0148607115592672$

Kuk, J. L., Lee, S., Heymsfield, S. B., and Ross, R. (2005). Waist circumference and abdominal adipose tissue distribution: influence of age and sex. Am. J. Clin. Nutr. 81, 1330-1334. doi: 10.1093/ajcn/81.6.1330

Kvist, H., Chowdhury, B., Grangård, U., Tylén, U., and Sjöström, L. (1988). Total and visceral adipose-tissue volumes derived from measurements with computed tomography in adult men and women: predictive equations. Am. J. Clin. Nutr. 48, 1351-1361. doi: 10.1093/ajcn/48.6.1351

Lauby-Secretan, B., Scoccianti, C., Loomis, D., Grosse, Y., Bianchini, F., Straif, K., et al. (2016). Body fatness and cancer-viewpoint of the IARC working group. N. Engl. J. Med. 375, 794-798. doi: 10.1056/NEJMsr1606602

Lean, M. E., Han, T. S., and Deurenberg, P. (1996). Predicting body composition by densitometry from simple anthropometric measurements. Am. J. Clin. Nutr. 63, 4-14. doi: 10.1093/ajcn/63.1.4

Lee, D.-Y., Lee, M.-Y., and Sung, K.-C. (2018). Prediction of mortality with a body shape index in young asians: comparison with body mass index and waist circumference. Obes. Silver Spring Md 26, 1096-1103. doi: 10.1002/oby.22193

Lee, D. H., Keum, N., Hu, F. B., Orav, E. J., Rimm, E. B., Sun, Q., et al. (2017). Development and validation of anthropometric prediction equations for lean body mass, fat mass and percent fat in adults using the National Health and Nutrition Examination Survey (NHANES) 1999-2006. Br. J. Nutr. 118, 858-866. doi: 10.1017/S0007114517002665

Lee, J. J., Freeland-Graves, J. H., Pepper, M. R., Stanforth, P. R., and Xu, B. (2015). Prediction of android and gynoid body adiposity via a three-dimensional stereovision body imaging system and dual-energy X-ray absorptiometry. J. Am. Coll. Nutr. 34, 367-377. doi: 10.1080/07315724.2014.966396

Lemieux, S., Prud'homme, D., Bouchard, C., Tremblay, A., and Després, J. P. (1996). A single threshold value of waist girth identifies normal-weight and overweight subjects with excess visceral adipose tissue. Am. J. Clin. Nutr. 64, 685-693. doi: 10.1093/ajcn/64.5.685

Li, G., Chen, X., Jang, Y., Wang, J., Xing, X., Yang, W., et al. (2002). Obesity, coronary heart disease risk factors and diabetes in Chinese: an approach to the criteria of obesity in the Chinese population. Obes. Rev. Off. J. Int. Assoc. Study Obes. 3, 167-172. doi: 10.1046/j.1467-789X.2002.00067.x

Li, G., Wu, H.-K., Wu, X.-W., Cao, Z., Tu, Y.-C., Ma, Y., et al. (2019). The feasibility of two anthropometric indices to identify metabolic syndrome, insulin resistance and inflammatory factors in obese and overweight adults. Nutr. Burbank Los Angel. Cty. Calif. 57, 194-201. doi: 10.1016/j.nut.2018.05.004

Lin, W.-Y., Lee, L.-T., Chen, C.-Y., Lo, H., Hsia, H.-H., Liu, I.-L., et al. (2002). Optimal cut-off values for obesity: using simple anthropometric indices to predict cardiovascular risk factors in Taiwan. Int. J. Obes. Relat. Metab. Disord. J. Int. Assoc. Study Obes. 26, 1232-1238. doi: 10.1038/sj.ijo.0802040

Liu, P., Ma, F., Lou, H., and Liu, Y. (2013). The utility of fat mass index vs. body mass index and percentage of body fat in the screening of metabolic syndrome. BMC Public Health 13:629. doi: 10.1186/1471-2458-13-629

Lohman, T. G. (1989). Assessment of body composition in children. Pediatr. Exerc. Sci. 1, 19-30. doi: 10.1123/pes.1.1.19

Lou, D.-H., Yin, F.-Z., Wang, R., Ma, C.-M., Liu, X.-L., and Lu, Q. (2012). Neck circumference is an accurate and simple index for evaluating overweight and obesity in Han children. Ann. Hum. Biol. 39, 161-165. doi: 10.3109/03014460.2012.660990

Lu, Y., and Hahn, J. K. (2019). "Shape-based three-dimensional body composition extrapolation using multimodality registration," in Medical Imaging 2019: Image Processing (San Diego, CA: International Society for Optics and Photonics).

Lu, Y., McQuade, S., and Hahn, J. K. (2018). "3D shape-based body composition prediction model using machine learning," in 2018 40th Annual International Conference of the IEEE Engineering in Medicine and Biology Society (Honolulu, HI: EMBC), 3999-4002. doi: 10.1109/EMBC.2018.8513261

Lu, Y., Shu, H., Zheng, Y., Li, C., Liu, M., Chen, Z., et al. (2012). Comparison of fat-free mass index and fat mass index in Chinese adults. Eur. J. Clin. Nutr. 66, 1004-1007. doi: 10.1038/ejcn.2012.86

Maessen, M. F. H., Eijsvogels, T. M. H., Verheggen, R. J. H. M., Hopman, M. T. E., Verbeek, A. L. M., and de Vegt, F. (2014). Entering a new era of body indices: the feasibility of a body shape index and body roundness index to identify cardiovascular health status. PLOS ONE 9:e107212. doi: 10.1371 /journal.pone.0107212
Mamtani, M. R., and Kulkarni, H. R. (2005). Predictive performance of anthropometric indexes of central obesity for the risk of type 2 diabetes. Arch. Med. Res. 36, 581-589. doi: 10.1016/j.arcmed.2005.03.049

Medina-Inojosa, J., Somers, V. K., Ngwa, T., Hinshaw, L., and LopezJimenez, F. (2016). Reliability of a 3D body scanner for anthropometric measurements of central obesity. Obes. Open Access 2:122. doi: 10.16966/23805528.122

Moschonis, G., Karatzi, K., Polychronopoulou, M. C., and Manios, Y. (2016). Waist circumference, trunk and visceral fat cutoff values for detecting hyperinsulinemia and insulin resistance in children: the Healthy Growth Study. Eur. J. Nutr. 55, 2331-2334. doi: 10.1007/s00394-015-1046-3

Motamed, N., Perumal, D., Zamani, F., Ashrafi, H., Haghjoo, M., Saeedian, F. S., et al. (2015). Conicity index and waist-to-hip ratio are superior obesity indices in predicting 10-year cardiovascular risk among men and women. Clin. Cardiol. 38, 527-534. doi: 10.1002/clc.22437

Motamed, N., Sohrabi, M., Poustchi, H., Maadi, M., Malek, M., Keyvani, H., et al. (2017). The six obesity indices, which one is more compatible with metabolic syndrome? A population based study. Diabetes Metab. Syndr. 11, 173-177. doi: 10.1016/j.dsx.2016.08.024

Mueller, W. H., Harrist, R. B., Doyle, S. R., and Labarthe, D. R. (2004). Percentiles of body composition from bioelectrical impedance and body measurements in U.S. adolescents 8-17 years old: Project HeartBeat! Am. J. Hum. Biol. Off. J. Hum. Biol. Counc. 16, 135-150. doi: 10.1002/ajhb.20002

Mukuddem-Petersen, J., Snijder, M. B., van Dam, R. M., Dekker, J. M., Bouter, L. M., Stehouwer, C. D. A., et al. (2006). Sagittal abdominal diameter: no advantage compared with other anthropometric measures as a correlate of components of the metabolic syndrome in elderly from the Hoorn Study. Am. J. Clin. Nutr. 84, 995-1002. doi: 10.1093/ajcn/84.5.995

Ng, B. K., Hinton, B. J., Fan, B., Kanaya, A. M., and Shepherd, J. A. (2016). Clinical anthropometrics and body composition from 3D whole-body surface scans. Eur. J. Clin. Nutr. 70, 1265-1270. doi: 10.1038/ejen.2016.109

Ng, B. K., Sommer, M. J., Wong, M. C., Pagano, I., Nie, Y., Fan, B., et al. (2019). Detailed 3-dimensional body shape features predict body composition, blood metabolites, and functional strength: the Shape Up! studies. Am. J. Clin. Nutr. 110, 1316-1326. doi: 10.1093/ajcn/nqz218

Nicklas, B. J., Penninx, B. W. J. H., Ryan, A. S., Berman, D. M., Lynch, N. A., and Dennis, K. E. (2003). Visceral adipose tissue cutoffs associated with metabolic risk factors for coronary heart disease in women. Diabetes Care 26, 1413-1420. doi: 10.2337/diacare.26.5.1413

Ohashi, N., Yamamoto, H., Horiguchi, J., Kitagawa, T., Kunita, E., Utsunomiya, H., et al. (2010). Association between visceral adipose tissue area and coronary plaque morphology assessed by CT angiography. JACC Cardiovasc. Imag. 3, 908-917. doi: 10.1016/j.jcmg.2010.06.014

Ohrvall, M., Berglund, L., and Vessby, B. (2000). Sagittal abdominal diameter compared with other anthropometric measurements in relation to cardiovascular risk. Int. J. Obes. Relat. Metab. Disord. J. Int. Assoc. Study Obes. 24, 497-501. doi: 10.1038/sj.ijo.0801186

Organization, W. H. (1999). Definition, Diagnosis and Classification of Diabetes Mellitus and Its Complications: Report of a WHO Consultation. Part 1, Diagnosis and Classification of Diabetes Mellitus. Available online at: https://apps.who.int/ iris/handle/10665/66040 (accessed October 11, 2020).

Padwal, R., Leslie, W. D., Lix, L. M., and Majumdar, S. R. (2016). Relationship among body fat percentage, body mass index, and all-cause mortality: a cohort study. Ann. Intern. Med. 164, 532-541. doi: 10.7326/M15-1181

Pajunen, P., Rissanen, H., Laaksonen, M. A., Heliövaara, M., Reunanen, A., and Knekt, P. (2013). Sagittal abdominal diameter as a new predictor for incident diabetes. Diabetes Care 36, 283-288. doi: 10.2337/dc11-2451

Park, S. K., Ryoo, J.-H., Oh, C.-M., Choi, J.-M., and Jung, J. Y. (2018). Longitudinally evaluated the relationship between body fat percentage and the risk for type 2 diabetes mellitus: Korean Genome and Epidemiology Study (KoGES). Eur. J. Endocrinol. 178, 513-521. doi: 10.1530/EJE17-0868

Peltz, G., Aguirre, M. T., Sanderson, M., and Fadden, M. K. (2010). The role of fat mass index in determining obesity. Am. J. Hum. Biol. Off. J. Hum. Biol. Counc. 22, 639-647. doi: 10.1002/ajhb.21056

Perona, J. S., Schmidt Rio-Valle, J., Ramírez-Vélez, R., Correa-Rodríguez, M., Fernández-Aparicio, Á., and González-Jiménez, E. (2019). Waist circumference and abdominal volume index are the strongest anthropometric discriminators 
of metabolic syndrome in Spanish adolescents. Eur. J. Clin. Invest. 49:e13060. doi: 10.1111/eci. 13060

Petersson, H., Daryani, A., and Risérus, U. (2007). Sagittal abdominal diameter as a marker of inflammation and insulin resistance among immigrant women from the Middle East and native Swedish women: a cross-sectional study. Cardiovasc. Diabetol. 6:10. doi: 10.1186/1475-2840-6-10

Pischon, T., Boeing, H., Hoffmann, K., Bergmann, M., Schulze, M. B., Overvad, K., et al. (2008). General and abdominal adiposity and risk of death in Europe. N. Engl. J. Med. 359, 2105-2120. doi: 10.1056/NEJMoa0801891

Pouliot, M. C., Després, J. P., Lemieux, S., Moorjani, S., Bouchard, C., Tremblay, A., et al. (1994). Waist circumference and abdominal sagittal diameter: best simple anthropometric indexes of abdominal visceral adipose tissue accumulation and related cardiovascular risk in men and women. Am. J. Cardiol. 73, 460-468. doi: 10.1016/0002-9149(94)90676-9

Preis, S. R., Massaro, J. M., Hoffmann, U., D’Agostino, R. B., Levy, D., Robins, S. J., et al. (2010). Neck circumference as a novel measure of cardiometabolic risk: the framingham heart study. J. Clin. Endocrinol. Metab. 95, 3701-3710. doi: $10.1210 /$ jc.2009-1779

Rådholm, K., Tengblad, A., Dahlén, E., Länne, T., Engvall, J., Nystrom, F. H., et al. (2017). The impact of using sagittal abdominal diameter to predict major cardiovascular events in European patients with type 2 diabetes. Nutr. Metab. Cardiovasc. Dis. NMCD 27, 418-422. doi: 10.1016/j.numecd.2017.02.001

Ramírez-Vélez, R., Correa-Bautista, J. E., Sanders-Tordecilla, A., Ojeda-Pardo, M. L., Cobo-Mejía, E. A., Castellanos-Vega, R. D. P., et al. (2017). Percentage of body fat and fat mass index as a screening tool for metabolic syndrome prediction in colombian university students. Nutrients 9:1009. doi: 10.3390/nu9091009

Resnick, H. E., Valsania, P., Halter, J. B., and Lin, X. (2000). Relation of weight gain and weight loss on subsequent diabetes risk in overweight adults. J. Epidemiol. Community Health 54, 596-602. doi: 10.1136/jech.54.8.596

Rexrode, K. M., Carey, V. J., Hennekens, C. H., Walters, E. E., Colditz, G. A., Stampfer, M. J., et al. (1998). Abdominal adiposity and coronary heart disease in women. JAMA 280, 1843-1848. doi: 10.1001/jama.280.21.1843

Richelsen, B., and Pedersen, S. B. (1995). Associations between different anthropometric measurements of fatness and metabolic risk parameters in non-obese, healthy, middle-aged men. Int. J. Obes. Relat. Metab. Disord. J. Int. Assoc. Study Obes. 19, 169-174.

Rico-Martín, S., Calderón-García, J. F., Sánchez-Rey, P., Franco-Antonio, C., Martínez Alvarez, M., and Sánchez Muñoz-Torrero, J. F. (2020). Effectiveness of body roundness index in predicting metabolic syndrome: a systematic review and meta-analysis. Obes. Rev. Off. J. Int. Assoc. Study Obes. 21:e13023. doi: 10.1111/obr.13023

Risérus, U., Arnlöv, J., Brismar, K., Zethelius, B., Berglund, L., and Vessby, B. (2004). Sagittal abdominal diameter is a strong anthropometric marker of insulin resistance and hyperproinsulinemia in obese men. Diabetes Care 27, 2041-2046. doi: 10.2337/diacare.27.8.2041

Risérus, U., de Faire, U., Berglund, L., and Hellénius, M.-L. (2010). Sagittal abdominal diameter as a screening tool in clinical research: cutoffs for cardiometabolic risk. J. Obes. 2010:757939. doi: 10.1155/2010/757939

Rolland-Cachera, M. F., Semp,é, M., Guilloud-Bataille, M., Patois, E., PéquignotGuggenbuhl, F., and Fautrad, V. (1982). Adiposity indices in children. Am. J. Clin. Nutr. 36, 178-184. doi: 10.1093/ajcn/36.1.178

Romero-Corral, A., Lopez-Jimenez, F., Sierra-Johnson, J., and Somers, V. K. (2008). Differentiating between body fat and lean mass-how should we measure obesity? Nat. Clin. Pract. Endocrinol. Metab. 4, 322-323. doi: 10.1038/ncpendmet0809

Roriz, A. K. C., Passos, L. C. S., de Oliveira, C. C., Eickemberg, M., Moreira, P., de, A., et al. (2014). Evaluation of the accuracy of anthropometric clinical indicators of visceral fat in adults and elderly. PLOS ONE 9:e103499. doi: 10.1371/journal.pone.0103499

Rosito, G. A., Massaro, J. M., Hoffmann, U., Ruberg, F. L., Mahabadi, A. A., Vasan, R. S., et al. (2008). Pericardial fat, visceral abdominal fat, cardiovascular disease risk factors, and vascular calcification in a communitybased sample: the Framingham Heart Study. Circulation 117, 605-613. doi: 10.1161/CIRCULATIONAHA.107.743062

Ross, R., Berentzen, T., Bradshaw, A. J., Janssen, I., Kahn, H. S., Katzmarzyk, P. T., et al. (2008). Does the relationship between waist circumference, morbidity and mortality depend on measurement protocol for waist circumference? Obes. Rev. 9, 312-325. doi: 10.1111/j.1467-789X.2007.00411.x

Ross, R., Neeland, I. J., Yamashita, S., Shai, I., Seidell, J., Magni, P., et al. (2020). Waist circumference as a vital sign in clinical practice: a consensus statement from the IAS and ICCR working group on visceral obesity. Nat. Rev. Endocrinol. 16, 177-189. doi: 10.1038/s41574-019-0310-7

Ryder, J. (2010). Three-Dimensional Body Scanning : A Novel Technique for Body Composition Assessment. Available online at: https://mospace.umsystem.edu/ xmlui/handle/10355/44842 (accessed October 22, 2020).

Samouda, H., Dutour, A., Chaumoitre, K., Panuel, M., Dutour, O., and Dadoun, F. (2013). VAT=TAAT-SAAT: innovative anthropometric model to predict visceral adipose tissue without resort to CT-Scan or DXA. Obes. Silver Spring Md 21:E41. doi: 10.1002/oby.20033

Sato, Y., Fujimoto, S., Konta, T., Iseki, K., Moriyama, T., Yamagata, K., et al. (2017). Body shape index: Sex-specific differences in predictive power for all-cause mortality in the Japanese population. PLOS ONE 12:e177779. doi: 10.1371/journal.pone.0177779

Schneider, H. J., Friedrich, N., Klotsche, J., Pieper, L., Nauck, M., John, U., et al. (2010). The predictive value of different measures of obesity for incident cardiovascular events and mortality. J. Clin. Endocrinol. Metab. 95, 1777-1785. doi: 10.1210/jc.2009-1584

Schutz, Y., Kyle, U. U. G., and Pichard, C. (2002). Fat-free mass index and fat mass index percentiles in Caucasians aged 18-98 y. Int. J. Obes. Relat. Metab. Disord. J. Int. Assoc. Study Obes. 26, 953-960. doi: 10.1038/sj.ijo.0802037

Seidell, J. C., Andres, R., Sorkin, J. D., and Muller, D. C. (1994). The sagittal waist diameter and mortality in men: the Baltimore longitudinal study on aging. Int. J. Obes. Relat. Metab. Disord. J. Int. Assoc. Study Obes. 18, 61-67.

Seidell, J. C., and Visscher, T. L. (2000). Body weight and weight change and their health implications for the elderly. Eur. J. Clin. Nutr. 54(Suppl. 3), S33-39. doi: 10.1038/sj.ejcn.1601023

Seo, J. A., Kim, B. G., Cho, H., Kim, H. S., Park, J., Baik, S. H., et al. (2009). The cutoff values of visceral fat area and waist circumference for identifying subjects at risk for metabolic syndrome in elderly Korean: Ansan Geriatric (AGE) cohort study. BMC Public Health 9:443. doi: 10.1186/1471-2458-9-443

Shea, J. L., King, M. T. C., Yi, Y., Gulliver, W., and Sun, G. (2012). Body fat percentage is associated with cardiometabolic dysregulation in BMI-defined normal weight subjects. Nutr. Metab. Cardiovasc. Dis. NMCD 22, 741-747. doi: 10.1016/j.numecd.2010.11.009

Shuster, A., Patlas, M., Pinthus, J. H., and Mourtzakis, M. (2012). The clinical importance of visceral adiposity: a critical review of methods for visceral adipose tissue analysis. Br. J. Radiol. 85, 1-10. doi: 10.1259/bjr/38447238

Shypailo, R. J., and Wong, W. W. (2020). Fat and fat-free mass index references in children and young adults: assessments along racial and ethnic lines. Am. J. Clin. Nutr. 112, 566-575. doi: 10.1093/ajcn/nqaa128

Si, S., Tewara, M. A., Ji, X., Wang, Y., Liu, Y., Dai, X., et al. (2020). Body surface area, height, and body fat percentage as more sensitive risk factors of cancer and cardiovascular disease. Cancer Med. 9, 4433-4446. doi: 10.1002/cam4.3076

Siri, W. E. (1956). Body Composition From Fluid Spaces And Density: Analysis Of Methods. Available online at: https://escholarship.org/uc/item/6mh9f4nf (accessed September 28, 2020).

Slaughter, M. H., Lohman, T., Boileau, R., Horswill, C., Stillman, R. J., Loan, M., et al. (1988). Skinfold equations for estimation of body fatness in children and youth. Hum. Biol. 60, 709-723.

Smith, G. I., Mittendorfer, B., and Klein, S. (2019). Metabolically healthy obesity: facts and fantasies. J. Clin. Invest. 129, 3978-3989. doi: 10.1172/JCI129186

Snijder, M. B., Dekker, J. M., Visser, M., Bouter, L. M., Stehouwer, C. D. A., Yudkin, J. S., et al. (2004). Trunk fat and leg fat have independent and opposite associations with fasting and postload glucose levels: the Hoorn study. Diabetes Care 27, 372-377. doi: 10.2337/diacare.27.2.372

Song, X., Jousilahti, P., Stehouwer, C. D. A., Söderberg, S., Onat, A., Laatikainen, T., et al. (2013). Comparison of various surrogate obesity indicators as predictors of cardiovascular mortality in four European populations. Eur. J. Clin. Nutr. 67, 1298-1302. doi: 10.1038/ejcn.2013.203

Song, X., Jousilahti, P., Stehouwer, C. D. A., Söderberg, S., Onat, A., Laatikainen, T., et al. (2015). Cardiovascular and all-cause mortality in relation to various anthropometric measures of obesity in Europeans. Nutr. Metab. Cardiovasc. Dis. NMCD 25, 295-304. doi: 10.1016/j.numecd.2014.09.004 
Sørensen, T. I. A., Frederiksen, P., and Heitmann, B. L. (2020). Levels and changes in body mass index decomposed into fat and fat-free mass index: relation to long-term all-cause mortality in the general population. Int. J. Obes. 44, 2092-2100. doi: 10.1038/s41366-020-0613-8

Stefan, D. B., and Gilbert, D. A. (2015). Categorizing the Morbidly Obese Body Shape and Estimating Body Appearance Outcome before Weight Loss Surgery Using 3D Anthropometric Data. doi: 10.15221/15.038

Stefan, D. B., Wohlgemuth, S., and Gilbert, D. A. (2014). Theory and Practical Steps to Introducing a New 3D Public Health Indicator to Replace BMI Using Existing Population-Based Multidimensional Reference Measurement Sets. doi: 10.15221/14.299

Sung, H., Siegel, R. L., Torre, L. A., Pearson-Stuttard, J., Islami, F., Fedewa, S. A., et al. (2019). Global patterns in excess body weight and the associated cancer burden. CA. Cancer J. Clin. 69, 88-112. doi: 10.3322/caac.21499

Tan, C.-E., Ma, S., Wai, D., Chew, S.-K., and Tai, E.-S. (2004). Can we apply the national cholesterol education program adult treatment panel definition of the metabolic syndrome to Asians? Diabetes Care 27, 1182-1186. doi: $10.2337 /$ diacare.27.5.1182

Taylor, R. W., Jones, I. E., Williams, S. M., and Goulding, A. (2000). Evaluation of waist circumference, waist-to-hip ratio, and the conicity index as screening tools for high trunk fat mass, as measured by dual-energy Xray absorptiometry, in children aged 3-19 y. Am. J. Clin. Nutr. 72, 490-495. doi: 10.1093/ajcn/72.2.490

Taylor, R. W., Jones, I. E., Williams, S. M., and Goulding, A. (2002). Body fat percentages measured by dual-energy $\mathrm{X}$-ray absorptiometry corresponding to recently recommended body mass index cutoffs for overweight and obesity in children and adolescents aged 3-18 y. Am. J. Clin. Nutr. 76, 1416-1421. doi: 10.1093/ajcn/76.6.1416

Thaete, F. L., Colberg, S. R., Burke, T., and Kelley, D. E. (1995). Reproducibility of computed tomography measurement of visceral adipose tissue area. Int. J. Obes. Relat. Metab. Disord. J. Int. Assoc. Study Obes. 19, 464-467.

Thomas, D. M., Bredlau, C., Bosy-Westphal, A., Mueller, M., Shen, W., Gallagher, D., et al. (2013). Relationships between body roundness with body fat and visceral adipose tissue emerging from a new geometrical model. Obesity 21, 2264-2271. doi: 10.1002/oby.20408

Tian, S., Zhang, X., Xu, Y., and Dong, H. (2016). Feasibility of body roundness index for identifying a clustering of cardiometabolic abnormalities compared to BMI, waist circumference and other anthropometric indices: the China Health and Nutrition Survey, 2008 to 2009. Medicine 95:e4642. doi: 10.1097/MD.0000000000004642

Tinsley, G. M., Moore, M. L., Benavides, M. L., Dellinger, J. R., and Adamson, B. T. (2020). 3-Dimensional optical scanning for body composition assessment: A 4-component model comparison of four commercially available scanners. Clin. Nutr. 39, 3160-3167.doi: 10.1016/j.clnu.2020.02.008

Tonding, S. F., Silva, F. M., Antonio, J. P., Azevedo, M. J., Canani, L. H. S., and Almeida, J. C. (2014). Adiposity markers and risk of coronary heart disease in patients with type 2 diabetes mellitus. Nutr. J. 13:124. doi: 10.1186/1475-2891-13-124

Valdez, R. (1991). A simple model-based index of abdominal adiposity. J. Clin. Epidemiol. 44, 955-956. doi: 10.1016/0895-4356(91)90059-I

Valdez, R., Seidell, J. C., Ahn, Y. I., and Weiss, K. M. (1993). A new index of abdominal adiposity as an indicator of risk for cardiovascular disease. A crosspopulation study. Int. J. Obes. Relat. Metab. Disord. J. Int. Assoc. Study Obes. $17,77-82$.

van der Kooy, K., Leenen, R., Seidell, J. C., Deurenberg, P., and Visser, M. (1993). Abdominal diameters as indicators of visceral fat: comparison between magnetic resonance imaging and anthropometry. Br. J. Nutr. 70, 47-58. doi: 10.1079/BJN19930104

VanItallie, T. B., Yang, M. U., Heymsfield, S. B., Funk, R. C., and Boileau, R. A. (1990). Height-normalized indices of the body's fat-free mass and fat mass: potentially useful indicators of nutritional status. Am. J. Clin. Nutr. 52, 953-959. doi: 10.1093/ajen/52.6.953

Vasques, A. C. J., Cassani, R. S. L., Forti, A. C., Vilela, B. S., Pareja, J. C., Tambascia, M. A., et al. (2015). Sagittal abdominal diameter as a surrogate marker of insulin resistance in an admixtured population-brazilian metabolic syndrome study (BRAMS). PLoS ONE 10:e0125365. doi: 10.1371/journal.pone.0125365

Wang, F., Chen, Y., Chang, Y., Sun, G., and Sun, Y. (2018). New anthropometric indices or old ones: which perform better in estimating cardiovascular risks in Chinese adults. BMC Cardiovasc. Disord. 18:14 doi: 10.1186/s12872-018-0754-Z

Wang, H., Liu, A., Zhao, T., Gong, X., Pang, T., Zhou, Y., et al. (2017). Comparison of anthropometric indices for predicting the risk of metabolic syndrome and its components in Chinese adults: a prospective, longitudinal study. BMJ Open 7:e016062. doi: 10.1136/bmjopen-2017-016062

Wang, J., Thornton, J. C., Bari, S., Williamson, B., Gallagher, D., Heymsfield, S. B., et al. (2003). Comparisons of waist circumferences measured at 4 sites. Am. J. Clin. Nutr. 77, 379-384. doi: 10.1093/ajcn/77.2.379

Wang, Z., He, S., and Chen, X. (2019). Capacity of different anthropometric measures to predict diabetes in a Chinese population in southwest China: a 15-year prospective study. Diabet. Med. J. Br. Diabet. Assoc. 36, 1261-1267. doi: 10.1111/dme.14055

Wang, Z., Pi-Sunyer, F. X., Kotler, D. P., Wielopolski, L., Withers, R. T., Pierson, R. N., et al. (2002). Multicomponent methods: evaluation of new and traditional soft tissue mineral models by in vivo neutron activation analysis. Am. J. Clin. Nutr. 76, 968-974. doi: 10.1093/ajcn/76.5.968

Wei, M., Gaskill, S. P., Haffner, S. M., and Stern, M. P. (1997). Waist circumference as the best predictor of noninsulin dependent diabetes mellitus (NIDDM) compared to body mass index, waist/hip ratio and other anthropometric measurements in Mexican Americans-a 7-year prospective study. Obes. Res. 5, 16-23. doi: 10.1002/j.1550-8528.1997.tb00278.x

Wells, J., Williams, J., Chomtho, S., Darch, T., Grijalva-Eternod, C., Kennedy, K., et al. (2010). Pediatric reference data for lean tissue properties: Density and hydration from age 5 to $20 \mathrm{y}$. Am. J. Clin. Nutr. 91, 610-618. doi: 10.3945/ajcn.2009.28428

Wells, J. C. K., and Fewtrell, M. S. (2006). Measuring body composition. Arch. Dis. Child. 91, 612-617. doi: 10.1136/adc.2005.085522

Weststrate, J., and Deurenberg, P. (1989). Body composition in children: Proposal for a method for calculating body fat percentage from total body density or skinfold-thickness measurements. Am. J. Clin. Nutr. 50, 1104-1115. doi: 10.1093/ajcn/50.5.1104

Whitmer, R. A., Gustafson, D. R., Barrett-Connor, E., Haan, M. N., Gunderson, E. P., and Yaffe, K. (2008). Central obesity and increased risk of dementia more than three decades later. Neurology 71, 1057-1064. doi: 10.1212/01.wnl.0000306313.89165.ef

WHO | Noncommunicable diseases country profiles (2018). WHO. Available online at: http://www.who.int/nmh/publications/ncd-profiles-2018/en/ (accessed September 28, 2020).

WHO | Physical status: the use and interpretation of anthropometry (2020). WHO. Available online at: https://www.who.int/childgrowth/publications/physical_ status/en/ (accessed October 22, 2020).

WHO Consultation on Obesity (1997). Obesity : Preventing and Managing the Global Epidemic : Report of a WHO Consultation on Obesity. Available online at: https://apps.who.int/iris/handle/10665/63854 (accessed October 12, 2020).

WHO Expert Consultation (2004). Appropriate body-mass index for Asian populations and its implications for policy and intervention strategies. Lancet Lond. Engl. 363, 157-163. doi: 10.1016/S0140-6736(03)15268-3

Wiklund, P., Toss, F., Weinehall, L., Hallmans, G., Franks, P. W., Nordström, A., et al. (2008). Abdominal and gynoid fat mass are associated with cardiovascular risk factors in men and women. J. Clin. Endocrinol. Metab. 93, 4360-4366. doi: 10.1210/jc.2008-0804

Wildman, R. P., Gu, D., Reynolds, K., Duan, X., and He, J. (2004). Appropriate body mass index and waist circumference cutoffs for categorization of overweight and central adiposity among Chinese adults. Am. J. Clin. Nutr. 80, 1129-1136. doi: 10.1093/ajen/80.5.1129

Wilson, J. P., Mulligan, K., Fan, B., Sherman, J. L., Murphy, E. J., Tai, V. W., et al. (2012). Dual-energy X-ray absorptiometry-based body volume measurement for 4-compartment body composition. Am. J. Clin. Nutr. 95, 25-31. doi: 10.3945/ajen.111.019273

Wong, M. C., Ng, B. K., Kennedy, S. F., Hwaung, P., Liu, E. Y., Kelly, N. N., et al. (2019). Children and Adolescents' Anthropometrics Body Composition from 3-D Optical Surface Scans. Obes. Silver Spring Md 27, 1738-1749. doi: $10.1002 /$ oby. 22637

Woolcott, O. O., and Bergman, R. N. (2018). Relative fat mass (RFM) as a new estimator of whole-body fat percentage - A cross-sectional study in American adult individuals. Sci. Rep. 8:10980. doi: 10.1038/s41598-01829362-1 
Xie, B., Avila, J. I., Ng, B. K., Fan, B., Loo, V., Gilsanz, V., et al. (2015). Accurate body composition measures from whole-body silhouettes. Med. Phys. 42, 4668-4677. doi: 10.1118/1.4926557

Yanovski, S. Z., and Yanovski, J. A. (2002). Obesity. N. Engl. J. Med. 346, 591-602. doi: 10.1056/NEJMra012586

Yi, S.-W., Ohrr, H., Shin, S.-A., and Yi, J.-J. (2015). Sex-age-specific association of body mass index with all-cause mortality among 12.8 million Korean adults: a prospective cohort study. Int. J. Epidemiol. 44, 1696-1705. doi: 10.1093/ije/dyv138

Yim, J. Y., Kim, D., Lim, S. H., Park, M. J., Choi, S. H., Lee, C. H., et al. (2010). Sagittal abdominal diameter is a strong anthropometric measure of visceral adipose tissue in the Asian general population. Diabetes Care 33, 2665-2670. doi: $10.2337 / \mathrm{dc} 10-0606$

Zamboni, M., Turcato, E., Armellini, F., Kahn, H. S., Zivelonghi, A., Santana, H., et al. (1998). Sagittal abdominal diameter as a practical predictor of visceral fat. Int. J. Obes. Relat. Metab. Disord. J. Int. Assoc. Study Obes. 22, 655-660. doi: 10.1038/sj.ijo.0800643

Zhang, C., Rexrode, K. M., van Dam, R. M., Li, T. Y., and Hu, F. B. (2008). Abdominal obesity and the risk of all-cause, cardiovascular, and cancer mortality: sixteen years of follow-up in US women. Circulation 117, 1658-1667. doi: 10.1161/CIRCULATIONAHA.107.739714

Zhang, Y.-X., and Wang, S.-R. (2011). Relation of body mass index, fat mass index and fat-free mass index to blood pressure in children aged 7-12 in Shandong, China. Ann. Hum. Biol. 38, 313-316. doi: 10.3109/03014460.2010.544258

Zhou, B.-F., and Cooperative Meta-Analysis Group of the Working Group on Obesity in China (2002). Predictive values of body mass index and waist circumference for risk factors of certain related diseases in Chinese adults-study on optimal cut-off points of body mass index and waist circumference in Chinese adults. Biomed. Environ. Sci. BES 15, 83-96.

Zhu, S., Heo, M., Plankey, M., Faith, M. S., and Allison, D. B. (2003). Associations of body mass index and anthropometric indicators of fat mass and fat free mass with all-cause mortality among women in the first and second National Health and Nutrition Examination Surveys follow-up studies. Ann. Epidemiol. 13, 286-293. doi: 10.1016/S1047-2797(02) 00417-9

Zimmet, P., Alberti, K. G. M., Kaufman, F., Tajima, N., Silink, M., Arslanian, S., et al. (2007). The metabolic syndrome in children and adolescents - an IDF consensus report. Pediatr. Diabetes 8, 299-306. doi: 10.1111/j.1399-5448.2007.00271.x

Conflict of Interest: The authors declare that the research was conducted in the absence of any commercial or financial relationships that could be construed as a potential conflict of interest.

Copyright (C) 2021 Piqueras, Ballester, Durá-Gil, Martinez-Hervas, Redón and Real. This is an open-access article distributed under the terms of the Creative Commons Attribution License (CC BY). The use, distribution or reproduction in other forums is permitted, provided the original author(s) and the copyright owner(s) are credited and that the original publication in this journal is cited, in accordance with accepted academic practice. No use, distribution or reproduction is permitted which does not comply with these terms. 